Cochrane Database of Systematic Reviews

\title{
Hypothermia for neuroprotection in adults after cardiopulmonary resuscitation (Review)
}

Arrich J, Holzer M, Havel C, Müllner M, Herkner H

Arrich J, Holzer M, Havel C, Müllner M, Herkner H.

Hypothermia for neuroprotection in adults after cardiopulmonary resuscitation.

Cochrane Database of Systematic Reviews 2016, Issue 2. Art. No.: CD004128.

DOI: 10.1002/14651858.CD004128.pub4.

www.cochranelibrary.com 
TABLE OF CONTENTS

HEADER 1

ABSTRACT

PLAIN LANGUAGE SUMMARY

SUMMARY OF FINDINGS

BACKGROUND

OBJECTIVES

METHODS

RESULTS

Figure 1.

Figure 2.

Figure 3.

Figure 4.

Figure 5.

Figure 6.

Figure 7.

DISCUSSION

AUTHORS' CONCLUSIONS

ACKNOWLEDGEMENTS

REFERENCES

CHARACTERISTICS OF STUDIES

DATA AND ANALYSES

Analysis 1.1. Comparison 1 Neurological outcome: therapeutic hypothermia versus no hypothermia, Outcome 1 All studies with subgroups.

Analysis 1.2. Comparison 1 Neurological outcome: therapeutic hypothermia versus no hypothermia, Outcome 2 Conventional cooling.

Analysis 2.1. Comparison 2 Survival: therapeutic hypothermia versus no hypothermia, Outcome 1 All studies with subgroups. .

Analysis 2.2. Comparison 2 Survival: therapeutic hypothermia versus no hypothermia, Outcome 2 Conventional cooling. ...... ADDITIONAL TABLES

APPENDICES

WHAT'S NEW

HISTORY

CONTRIBUTIONS OF AUTHORS

DECLARATIONS OF INTEREST

SOURCES OF SUPPORT

DIFFERENCES BETWEEN PROTOCOL AND REVIEW

NOTES

INDEX TERMS 
[Intervention Review]

\section{Hypothermia for neuroprotection in adults after cardiopulmonary resuscitation}

Jasmin Arrich ${ }^{1}$, Michael Holzer ${ }^{1}$, Christof Havel${ }^{1}$, Marcus Müllner², Harald Herkner ${ }^{1}$

1Department of Emergency Medicine, Medical University of Vienna, Vienna, Austria. 2Internistisches Zentrum Brigittenau, Vienna, Austria

Contact address: Jasmin Arrich, Department of Emergency Medicine, Medical University of Vienna, Währinger Gürtel 18-20 / 6D, Vienna, 1090, Austria. jasmin.arrich@meduniwien.ac.at.

Editorial group: Cochrane Emergency and Critical Care Group.

Publication status and date: Edited (no change to conclusions), published in Issue 12, 2018.

Citation: Arrich J, Holzer M, Havel C, Müllner M, Herkner H. Hypothermia for neuroprotection in adults after cardiopulmonary resuscitation. Cochrane Database of Systematic Reviews 2016, Issue 2. Art. No.: CD004128. DOI: 10.1002/14651858.CD004128.pub4.

Copyright @ 2018 The Cochrane Collaboration. Published by John Wiley \& Sons, Ltd.

\section{A B S T R A C T}

\section{Background}

Good neurological outcome after cardiac arrest is difficult to achieve. Interventions during the resuscitation phase and treatment within the first hours after the event are critical. Experimental evidence suggests that therapeutic hypothermia is beneficial, and several clinical studies on this topic have been published. This review was originally published in 2009; updated versions were published in 2012 and 2016.

\section{Objectives}

We aimed to perform a systematic review and meta-analysis to assess the influence of therapeutic hypothermia after cardiac arrest on neurological outcome, survival and adverse events.

\section{Search methods}

We searched the following databases: the Cochrane Central Register of Controlled Trials (CENTRAL; 2014, Issue 10); MEDLINE (1971 to May 2015); EMBASE (1987 to May 2015); the Cumulative Index to Nursing and Allied Health Literature (CINAHL) (1988 to May 2015); and BIOSIS (1989 to May 2015). We contacted experts in the field to ask for information on ongoing, unpublished or published trials on this topic.The original search was performed in January 2007.

\section{Selection criteria}

We included all randomized controlled trials (RCTs) conducted to assess the effectiveness of therapeutic hypothermia in participants after cardiac arrest, without language restrictions. We restricted studies to adult populations cooled by any cooling method, applied within six hours of cardiac arrest.

\section{Data collection and analysis}

We entered validity measures, interventions, outcomes and additional baseline variables into a database. Meta-analysis was performed only for a subset of comparable studies with negligible heterogeneity. We assessed the quality of the evidence by using standard methodological procedures as expected by Cochrane and incorporated the GRADE (Grades of Recommendation, Assessment, Development and Evaluation) approach.

\section{Main results}

We found six RCTs (1412 participants overall) conducted to evaluate the effects of therapeutic hypothermia - five on neurological outcome and survival, one on only neurological outcome. The quality of the included studies was generally moderate, and risk of bias was low in three out of six studies. When we compared conventional cooling methods versus no cooling (four trials; 437 participants), we found 
that participants in the conventional cooling group were more likely to reach a favourable neurological outcome (risk ratio (RR) $1.94,95 \%$ confidence interval $(\mathrm{Cl}) 1.18$ to 3.21). The quality of the evidence was moderate.

Across all studies that used conventional cooling methods rather than no cooling (three studies; 383 participants), we found a $30 \%$ survival benefit (RR $1.32,95 \% \mathrm{Cl} 1.10$ to 1.65 ). The quality of the evidence was moderate.

Across all studies, the incidence of pneumonia (RR 1.15, 95\% Cl 1.02 to 1.30; two trials; 1205 participants) and hypokalaemia (RR 1.38, 95\% $\mathrm{Cl} 1.03$ to 1.84; two trials; 975 participants) was slightly increased among participants receiving therapeutic hypothermia, and we observed no significant differences in reported adverse events between hypothermia and control groups. Overall the quality of the evidence was moderate (pneumonia) to low (hypokalaemia).

\section{Authors' conclusions}

Evidence of moderate quality suggests that conventional cooling methods provided to induce mild therapeutic hypothermia improve neurological outcome after cardiac arrest, specifically with better outcomes than occur with no temperature management. We obtained available evidence from studies in which the target temperature was $34^{\circ} \mathrm{C}$ or lower. This is consistent with current best medical practice as recommended by international resuscitation guidelines for hypothermia/targeted temperature management among survivors of cardiac arrest. We found insufficient evidence to show the effects of therapeutic hypothermia on participants with in-hospital cardiac arrest, asystole or non-cardiac causes of arrest.

\section{PLAIN LANGUAGE SUMMARY}

\section{Cooling the body after resuscitation following cardiac arrest}

\section{Review question}

In this review, we asked whether people resuscitated from cardiac arrest benefit when their bodies are cooled to a temperature of $34^{\circ} \mathrm{C}$ or lower.

\section{Background}

\section{Population and outcomes}

Around $30 \%$ to $50 \%$ of all people with coronary heart disease suffer sudden cardiac death at some stage of their illness. Sudden cardiac death means that the heart and subsequently the circulation stop. If these people are not resuscitated, brain cells begin to be irreversibly damaged, and subsequently the person dies. After resuscitation, treatment within the first few hours is critical for avoiding or limiting brain damage. One form of therapy that may help to prevent cell damage consists of cooling the body for several hours after successful resuscitation to $34^{\circ} \mathrm{C}$ or lower.

\section{Intervention}

We compared people who had their bodies cooled to $32^{\circ} \mathrm{C}$ to $34^{\circ} \mathrm{C}$ or below after resuscitation with people who were not cooled following successful resuscitation.

\section{Search date}

Evidence is current to May 2015.

\section{Study characteristics}

We included in our analysis six studies (1412 people overall), four of which (437 people) examined effects of cooling the body by conventional methods after successful resuscitation for cardiac arrest. One study that used haemofiltration (cooling the blood externally - similar to dialysis) as the cooling method and one study in which cooling to $33^{\circ} \mathrm{C}$ was compared with temperature management at $36^{\circ} \mathrm{C}$ were treated separately in the review.

\section{Study funding sources}

The study that used external cooling was supported by a dialysis-related company. Of the five studies included in the main analysis, two received funding from government or non-profit organizations; three studies did not provide information on funding.

\section{Key results}

When we compared people whose bodies were cooled to $32^{\circ} \mathrm{C}$ to $34^{\circ} \mathrm{C}$ after resuscitation versus those whose bodies were not cooled at all, we found that $63 \%$ of those receiving cooling would suffer no, or only minor, brain damage, while only $33 \%$ of those not cooled would suffer no, or only minor, brain damage. Cooling had an important effect on simple survival, with or without brain damage: $57 \%$ would survive if their bodies were cooled compared with $42 \%$ if their bodies were not cooled at all. No serious side effects occurred, but cooling the body 
was associated with increased risk of pneumonia (49\% vs $42 \%$ of those studied) and increased risk of low concentrations of potassium in the blood ( $18 \%$ vs $13 \%)$.

\section{Quality of the evidence}

Some studies had quality shortcomings including small numbers of participants and use of inadequate methods to balance participants between intervention and control groups. However, when differences between studies are acknowledged (heterogeneity), it is clear that these shortcomings had no major impact on the main results. 


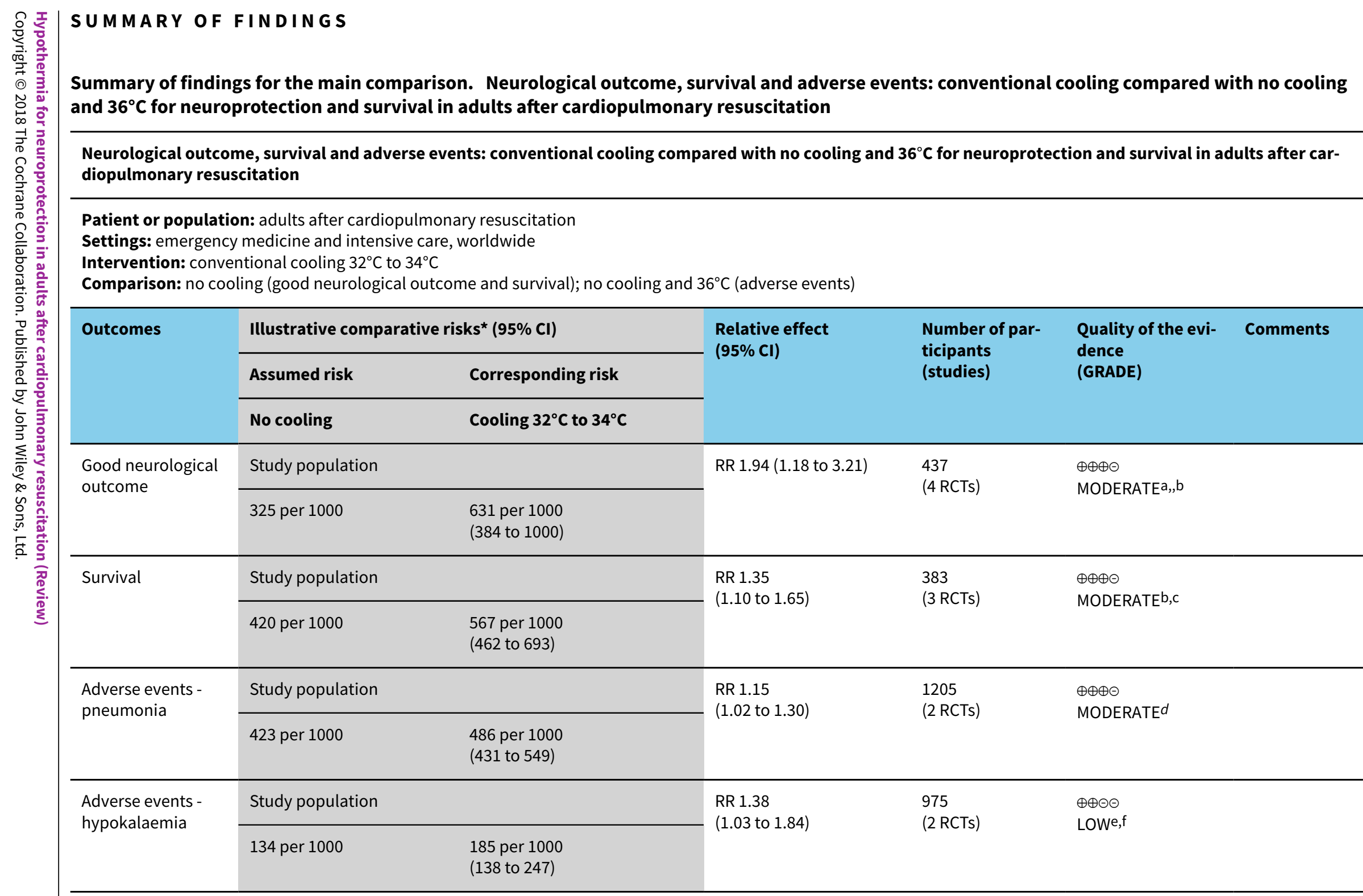

*The basis for the assumed risk (e.g. median control group risk across studies) is provided in footnotes. The corresponding risk (with its $95 \%$ confidence interval) is based on assumed risk in the comparison group and relative effect of the intervention (and its $95 \% \mathrm{Cl}$ )

Cl: Confidence interval 
High quality: Further research is very unlikely to change our confidence in the estimate of effect

Moderate quality: Further research is likely to have an important impact on our confidence in the estimate of effect and may change the estimate

Low quality: Further research is very likely to have an important impact on our confidence in the estimate of effect and is likely to change the estimate

Very low quality: We are very uncertain about the estimate

aOne quasi-randomized trial (Bernard 2002) and one abstract (Mori 2000) but both not contributing to most data (see also Effects of interventions - 'Sensitivity analysis')

${ }^{b}$ Total number of events $<300$; imprecision therefore was rated as serious, and this resulted in downgrading of the overall quality of the evidence one level from high to moderate

cOne quasi-randomized trial not contributing to the majority of data (see also Effects of interventions - 'Sensitivity analysis')

$d$ Indirectness was caused mostly by control group treatment (Nielsen 2013), which resulted in downgrading of the overall quality of the evidence one level from high to moderate

endirectness was rated as very serious because of differences in intervention (haemofiltration, conventional cooling) and control group treatments (no cooling, $36^{\circ} \mathrm{C}$ ), which

resulted in downgrading of the overall quality of the evidence two levels from high to low

$f$ Laurent 2005 had some risk of bias but is not contributing to the majority of data 


\section{B A C K G R O U N D}

\section{Description of the condition}

The incidence of out-of-hospital sudden cardiac arrest in industrial countries varies greatly over different study groups and is reported to range between $0.05 \%$ and $0.19 \%$ per year (Chugh 2004; McNally 2011; Rea 2004). Among all participants for whom resuscitation was attempted, $14 \%$ to $40 \%$ achieved return of spontaneous circulation and were admitted to hospital (Finn 2001; Fischer 1997; Giraud 1996; Herlitz 2003b; Kuisma 1996; Leung 2001; Rewers 2000). Of patients admitted to hospital, only between $7 \%$ and $30 \%$ were discharged from hospital with good neurological outcome (Absalom 1999; Böttiger 1999; Fischer 1997; Herlitz 1999; Jennings 2001; McNally 2011; Weston 1997). To improve neurological outcome and survival of patients after cardiac arrest, providers have applied many methods related to postresuscitation care. These comprise optimizing haemodynamics and providing ventilation, coronary reperfusion, electrolytes, seizure control, temperature management and glucose control and are summarized in the main resuscitation guidelines (Callaway 2015; Soar 2015).

\section{Description of the intervention}

Therapeutic hypothermia (or targeted temperature management/ induced hypothermia) is still a relatively new concept for preservation of cerebral function among patients resuscitated from cardiac arrest. After the patient's condition has been stabilized, body temperature is lowered to $32^{\circ} \mathrm{C}$ to $34^{\circ} \mathrm{C}$ for a duration of 24 hours. Conventional cooling comprises surface cooling methods requiring cooling pads, ice packs, water immersion or intravascular cooling with cooling catheters or simply cold fluids. Cooling can be combined with haemofiltration or extracorporeal cardiopulmonary support.

\section{How the intervention might work}

Therapeutic hypothermia is believed to work in many ways. Cerebral reperfusion after successful resuscitation, although essential and effective in restoring energy stores, can trigger harmful chemical cascades. Generation of free radicals and other mediators, which leads to multi-focal damage to the brain, was first described by Negovsky as "post-resuscitation syndrome" (Negovsky 1988). In contrast to accidental hypothermia, therapeutic mild hypothermia $\left(32^{\circ} \mathrm{C}\right.$ to $\left.34^{\circ} \mathrm{C}\right)$ is administered in a controlled way. Intra-ischaemic hypothermia for brain protection has been provided for several years with certain surgical procedures and circulatory arrest states. Clinical and experimental results show protective effects of hypothermia during and after ischaemic situations (Rosomoff 1954). Therapeutic hypothermia can inhibit the biosynthesis, release and uptake of several catecholamines and neurotransmitters (Okuda 1986; Sun 2010; Szelenyi 2012), especially glutamate and dopamine, thus preventing potential tissue damage (D'Cruz 2002; Hachimi-Idrissi 2004). Other beneficial effects of hypothermia include preservation of the blood-brain barrier (Baumann 2009; Karibe 1994); protection of adenosine triphosphate (ATP) stores (McCullough 1999; Mizuhara 1996) necessary for energy provision; restitution of post-ischaemic cerebral microcirculation (Takasu 1996); and possibly decreased intracranial pressure (Lee 2010; Schreckinger 2009). Subsequently, hypothermia seems to act in a multi-factorial way by influencing several damaging pathways simultaneously (Holzer 2010) to reduce cell death within the brain.

\section{Why it is important to do this review}

The first Cochrane review (Arrich 2009) was conducted to examine the emergence of mild therapeutic hypothermia as part of routine care for survivors of cardiac arrest. Two randomized controlled trials (RCTs) had shown that induced hypothermia has a neuroprotective effect in patients primarily resuscitated from cardiac arrest (Bernard 2002; HACA 2002), and therapeutic hypothermia was recommended in the guidelines of the International Liaison Committee on Resuscitation (ILCOR) (Nolan 2003) and in other resuscitation guidelines of that time (Deakin 2010; Peberdy 2010). It is recommended as "targeted temperature management (induced hypothermia)" in the current resuscitation guidelines (Callaway 2015; Soar 2015). Therapeutic hypothermia remains a relatively new concept. Studies examining different treatment modalities are emerging; therefore systematic and regular updates of the literature are important for monitoring new and effective developments. A recent publication following a large RCT on two different cooling levels described no differences between the two treatment regimens (Nielsen 2013). We present the second update of the original Cochrane review (Arrich 2009; Arrich 2012), which incorporates up-to-date evidence.

\section{O B JECT IVES}

We aimed to perform a systematic review and meta-analysis to assess the influence of therapeutic hypothermia after cardiac arrest on neurological outcome, survival and adverse events.

\section{METHODS}

\section{Criteria for considering studies for this review \\ Types of studies}

We included randomized and 'quasi-randomized' controlled trials. 'Quasi-randomized' refers to allocation procedures such as alternating days, odd and even days and the like.

\section{Types of participants}

We included studies in adult participants who suffered from cardiac arrest (regardless of whether in-hospital or out-of-hospital cardiac arrest) and were successfully resuscitated.

We excluded studies of children and adolescents (younger than 18 years), as presumed causes of cardiac arrest are different from causes in adults.

Although participants with a prior neurological history may not greatly benefit from the intervention, we did not exclude them for the following reasons.

- The number of such participants is most likely negligible.

- In a real-life situation, information on neurological performance before cardiac arrest often is not available when postresuscitation therapy is initiated

\section{Types of interventions}

The intervention of interest was therapeutic hypothermia regardless of how body temperature was reduced - applied within six hours of arrival at hospital. We defined 'therapeutic' as any 
target body temperature of $34^{\circ} \mathrm{C}$ or lower. We defined the 'control' intervention as standard treatment (at the time of the trial) provided after cardiac arrest.

\section{Types of outcome measures}

\section{Primary outcomes}

The primary outcome measure was neurological recovery. We expected the ideal outcome to be reported as best neurological outcome during hospital stay and in cerebral performance categories (CPCs) (Stiell 2009). CPC categories are defined as follows.

- Good cerebral performance: conscious, alert, capable of normal life. Normal cerebral function. May have minor psychological or neurological deficits that do not significantly compromise cerebral or physical function.

- Moderate cerebral disability: conscious, alert, sufficient cerebral function for activities of daily life (e.g. dress, travel by public transportation, food preparation). May have hemiplegia, seizures, ataxia, dysarthria, dysphasia or permanent memory or mental changes.

- Severe cerebral disability: conscious, with at least limited cognition. Dependent on others for daily life support (i.e. institutionalised or at home with exceptional family effort) because of impaired brain function. Includes individuals with wide range of cerebral abnormalities, from ambulatory participants with severe memory disturbance or dementia precluding independent existence to paralysed participants who can communicate only with their eyes (e.g. the locked-in syndrome).

- Coma or vegetative state: not conscious, unaware of surroundings, no cognition. No verbal or psychological interaction with environment. May appear awake because of spontaneous eye opening or sleep-wake cycle. Includes individuals showing all degrees of unresponsiveness that are neither CPC three (conscious) nor CPC five (coma, which satisfies brain death criteria).

- Certified brain death.

If study authors grouped the primary outcome into one or two (good recovery) and three to five (unfavourable recovery), we adapted it for our meta-analysis. If the primary outcome was not reported in CPC categories, we accepted reports of 'good' neurological outcome, and we assumed that this was comparable with a CPC score of one or two.

\section{Secondary outcomes}

- Survival to hospital discharge at six months and long term.

- Quality of life at six months and long term.

- Dependency.

- Cost-effectiveness.

We defined 'long term' as a minimum of one year.

\section{Adverse events}

We aimed to report adverse events as described by study authors.

\section{Search methods for identification of studies}

\section{Electronic searches}

We searched the following databases: the Cochrane Central Register of Controlled Trials (CENTRAL; 2014, Issue 9); MEDLINE (1971 to May 2015); EMBASE (1987 to May 2015); the Cumulative Index to Nuring and Allied Health Literature (CINAHL) (1988 to May 2015); and BIOSIS (1989 to May 2015). Original searches were performed in January 2007 (Arrich 2009) and were updated in July 2011 (Arrich 2012).

We performed searches by entering search terms as multiple postings (.mp, term appears in the title, abstract or medical subject heading $(\mathrm{MeSH})$ ) and some as medical subject headings (MeSH) for MEDLINE and exploded terms for EMBASE and CINAHL (search terms for CENTRAL, Appendix 1; MEDLINE, Appendix 2; EMBASE, Appendix 3; CINAHL, Appendix 4; BIOSIS, Appendix 5). We used a search strategy for identifying RCTs with MEDLINE, CINAHL and EMBASE (Higgins 2011), and we applied no language restrictions. We searched three trials registers as well: EudraCT; ClinicalTrials.gov; International Clinical Trials Registry Platform.

\section{Searching other resources}

In an attempt to identify additional studies, we asked experts in the field whether they were aware of any ongoing, unpublished or published trials on this topic.

\section{Data collection and analysis}

\section{Selection of studies}

We imported all retrieved results into EndNote (version X5; Thomson Corporation, Stamford, CT, USA) and eliminated duplicates. Two review authors (JA, $\mathrm{MH}$ or $\mathrm{CH} ; \mathrm{HH}$ as arbiter in case of discrepancies) independently scanned each reference for inclusion in the review.

\section{Data extraction and management}

We independently extracted data using a data extraction form (see Appendix 6). As we intended to use the original individual patient data (IPD) provided by identified trials, we contacted the respective corresponding authors and asked for collaboration. Two review authors independently entered all relevant data into the Cochrane software program Review Manager (RevMan 5.3). We compared the two versions and resolved disagreements by discussion.

We entered the following variables into RevMan 5.3.

- Study characteristics.

- Data on outcomes.

- Items on risk of bias.

- Within-study subgroup effect estimates as calculated from IPD outside RevMan.

\section{Assessment of risk of bias in included studies}

To assess the internal validity of identified trials, we assessed allocation sequence generation, allocation concealment, blinding of outcome assessment, exclusion of randomized participants from the analysis, comparability of groups, loss to follow-up and other potential sources of bias. However, blinding of treating personnel regarding application of therapeutic hypothermia was considered almost impossible. 


\section{Measures of treatment effect}

We calculated risk ratios (RRs) and their $95 \%$ confidence intervals (Cls).

\section{Unit of analysis issues}

We did not include cluster-randomized trials in the analysis; in the case of multiple treatment groups, we planned to combine groups to create a single comparison; by nature of the condition and outcomes, we identified no cross-over trials.

\section{Dealing with missing data}

All analyses were performed according to the intention-to-treat (ITT) principle. If data were missing, we attempted to obtain the information by contacting study authors. We included assessment of loss to follow-up in our quality assessment and reported this in the table Characteristics of included studies. If a considerable quantity of data was missing, we would investigate the possible mechanism of the missing data (whether random or not). We planned to perform a sensitivity analysis to assess the influence of this possible selection bias on our estimates.

\section{Assessment of heterogeneity}

We assessed data for clinical and statistical heterogeneity. We performed quantitative synthesis of data only if clinical heterogeneity was negligible. Clinical heterogeneity may be caused by differences in study populations, interventions and controls, or by variable definitions of the endpoint (Thompson 2001). Pooling of data may not be suitable in cases of severe heterogeneity.

\section{Assessment of reporting biases}

We assessed the presence of possible publication bias and heterogeneity by using funnel plots (plotting effect vs precision) (Egger 1997) and planned to present this information if we identified more than 10 studies.

\section{Data synthesis}

Quantitative analysis of IPD was intended when studies showed negligible heterogeneity and IPD were available at least for a clinically uniform subset. In the case that IPD were not available for at least one study, we planned to perform an analysis at the study level, particularly when we encountered updates. We planned to perform a quantitative synthesis of IPD by using standard statistical procedures provided in RevMan 5.3. The principal summary effect estimate was the risk ratio with a $95 \%$ confidence interval.

In the case of negligible heterogeneity, we used a fixed-effect model to calculate summary effects; otherwise we used randomeffects models. We assessed statistical heterogeneity by using the $1^{2}$ statistic (Higgins 2003) and considered statistical heterogeneity relevant with 12 statistic $>50 \%$.

\section{Subgroup analysis and investigation of heterogeneity}

For the primary endpoint and for survival, we performed subgroup analyses at the study level.

- Treatment of the control group: no cooling versus temperature management. These ancillary analyses were introduced at the current update following consideration of differences in control group treatment described in a newly included study (Nielsen
2013). We used the standard test for subgroup differences to assess differences in effects between study level subgroups.

When data became available, we performed subgroup analyses for the primary outcome using IPD. We used the following variables.

- Cause of cardiac arrest (presumed cardiac vs non-cardiac).

- Location of arrest (in-hospital vs out-of-hospital).

- Witnessed versus non-witnessed arrest.

- Primary electrocardiography (ECG) rhythm (ventricular fibrillation vs other).

We received IPD (Bernard 2002; HACA 2002; Hachimi-Idrissi 2001) via spreadsheets including participant-specific information on interventions, outcomes and subgroup properties. We calculated subgroup-specific effect estimates across included studies at the individual patient level but performed no tests to examine subgroup differences.

\section{Sensitivity analysis}

We performed sensitivity analyses to examine the impact of study quality issues, as measured by allocation concealment, on overall effect estimates and on effect sizes of all identified trials without consideration of heterogeneity and publication status. To investigate whether model choice might influence our results, we compared estimates derived from random-effects models versus those obtained from fixed-effect models.

\section{Summary of findings}

We used the GRADE (Grades of Recommendation, Assessment, Development and Evaluation) approach to interpret findings (Langendam 2013). The GRADE profiler (GRADEPRO) allowed us to import data from Review Manager (RevMan 5.3) to create a 'Summary of findings' table. This table provides outcome-specific information concerning overall quality of evidence gathered from studies included in the comparison, magnitude of effects of the interventions examined and the sum of available data on outcomes considered.

We included the following outcomes in a 'Summary of findings' table.

- Neurological outcome, survival (conventional cooling vs no cooling) and adverse events (vs no cooling and $36^{\circ} \mathrm{C}$ ).

\section{RE S U L T S}

\section{Description of studies}

\section{Results of the search}

Our original and updated searches (from 2007 to May 2015) resulted in 2425 hits (duplicates excluded). From these, we excluded 2417 according to our eligibility criteria (randomized studies on adult participants with cardiac arrest treated with therapeutic hypothermia) by judging the abstract or the title. Eight papers remained for closer inspection. Of those, we excluded three after further evaluation (see Characteristics of excluded studies; and Figure 1). Upon looking through the references of a systematic review on therapeutic hypothermia (Cheung 2006), we found one additional reference, published only as an abstract (Mori 2000). Hence overall, six randomized and quasi-randomized controlled trials with a total of 1412 participants remained for analysis 
(Bernard 2002; HACA 2002; Hachimi-Idrissi 2001; Laurent 2005; Mori 2000; Nielsen 2013) (see Characteristics of included studies).

Figure 1. Study flow diagram.

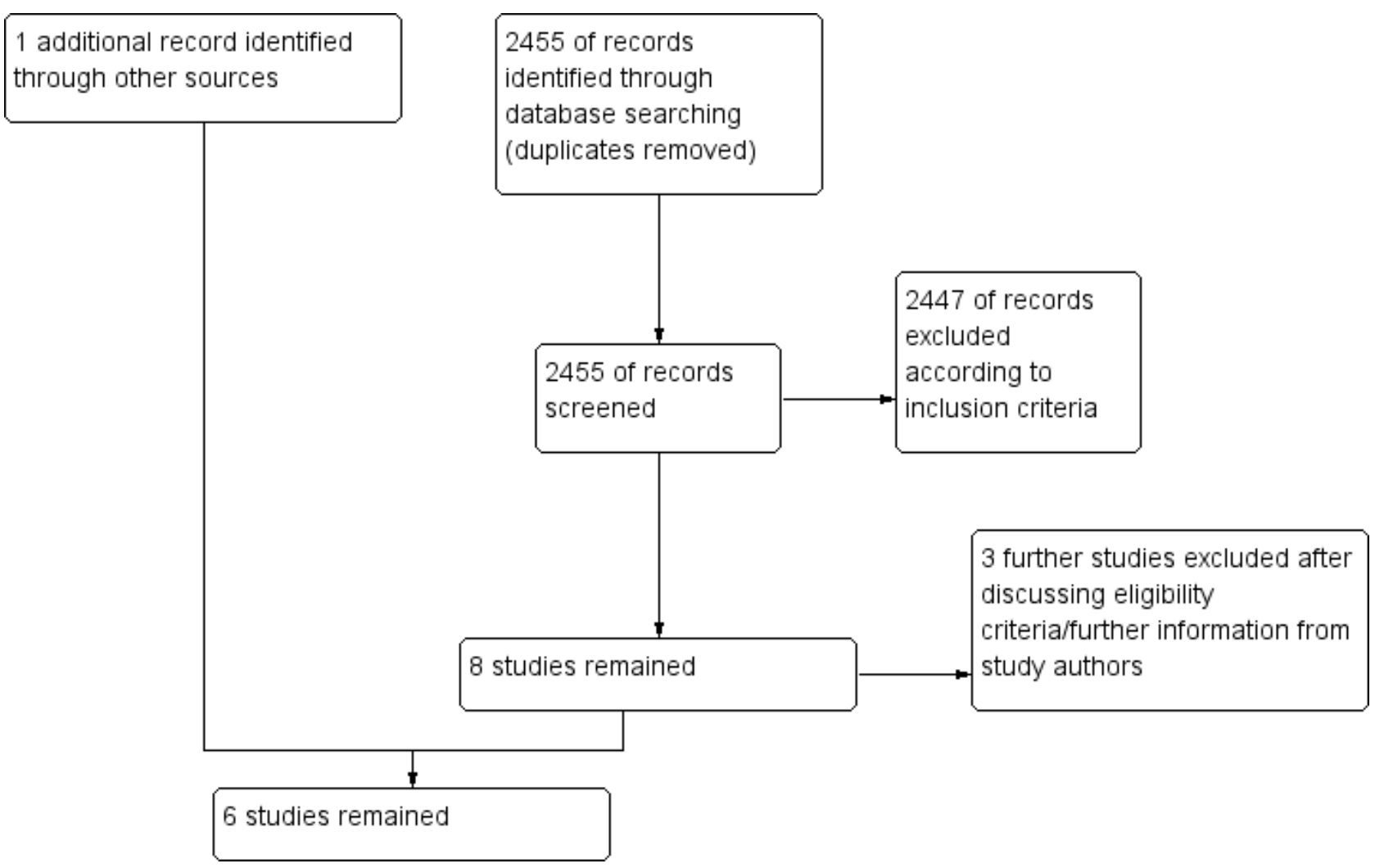

The decision on inclusion of one study was not unequivocal (Nielsen 2013) because control group participants in the study by Nielsen et al received active temperature management at $36^{\circ} \mathrm{C}$, which is clearly different from 'no temperature management'. It is a matter of concern whether temperature control at $36^{\circ} \mathrm{C}$ can be seen as 'standard therapy', as we outlined in our inclusion criteria for the control group. We decided to include the study in our review while treating it as a separate subgroup for the main analysis. However in an additional ancillary analysis, we calculated a pooled overall estimate to inform the current controversial discussion.

We found that one previously unclassified study (Tiainen 2007) and two additional studies (Tiainen 2003; Tiainen 2005) were reports of the HACA 2002 study.

\section{Included studies}

We included six studies (Bernard 2002; HACA 2002; Hachimi-Idrissi 2001; Laurent 2005; Mori 2000; Nielsen 2013) (see Characteristics of included studies) in this updated review.

The first study (Hachimi-Idrissi 2001) was a feasibility RCT carried out at one 700-bed teaching hospital in Brussels during a six month period. It included 33 consecutive participants with out-of-hospital cardiac arrest and asystole or pulseless electrical activity (PEA) of presumed cardiac origin who achieved return of spontaneous circulation (ROSC). The mean age of participants was 72 , and $39 \%$ were female. After admission and stabilization, participants were randomly assigned to (1) a helmet device placed around the head and neck containing a solution of aqueous glycerol, or (2) standard therapy without hypothermia. The target temperature of the intervention group was $34^{\circ} \mathrm{C}$, which should be maintained over a period of four hours; this was followed by a passive rewarming phase over eight hours. Outcome parameters were laboratory values and haemodynamics, survival to hospital discharge and overall performance categories (OPCs) and adverse events. No information on funding was provided.

Two studies were published at the same time (Bernard 2002; HACA 2002). The study by Bernard 2002 was a quasi-RCT carried out by the ambulance service of Melbourne and four adjacent emergency departments and intensive care units over a three-year period. It included 77 participants with out-of-hospital cardiac arrest and ventricular fibrillation as first cardiac rhythm who were comatose after they achieved ROSC. The mean age of participants was 66 , and $33 \%$ were female. Participants were randomly assigned by the ambulance staff to receive (1) therapeutic hypothermia by ice packs placed around the head, neck, torso and limbs, or (2) standard therapy without hypothermia. The target temperature of the intervention group was $33^{\circ} \mathrm{C}$, which should be maintained over a period of 24 hours; this was followed by a passive rewarming phase over eight hours. Outcome parameters were survival with good neurological function; in-hospital mortality; haemodynamic, biochemical and haematological effects of hypothermia; and adverse events. No information on funding was provided.

HACA 2002 was an RCT carried out by nine centres in five European countries and four adjacent emergency departments 
and intensive care units over a five-year period. It included 275 participants with out-of-hospital bystander-witnessed cardiac arrest of presumed cardiac cause, ventricular fibrillation or nonperfusing ventricular tachycardia as first cardiac rhythm, who were comatose after resuscitation. The mean age of participants was 59, and $24 \%$ were female. After admission, participants were randomly assigned to receive (1) therapeutic hypothermia by an external cooling device, or (2) standard therapy without hypothermia. The target temperature of the intervention group was $32^{\circ} \mathrm{C}$ to $34^{\circ} \mathrm{C}$, which should be maintained over a period of 12 hours; this was followed by a passive rewarming phase over 12 hours and, if necessary, active rewarming after 18 hours. Outcome parameters were survival, neurological outcome and adverse events. Funding was provided by grants of the Fourth Research and Technological Development (RTD) Framework Programme 1994 to 1998 of the European Union (Fourth Framework Programme), the Austrian Ministry of Science and Transport and the Austrian Science Foundation (FWF).

Laurent 2005 was an RCT carried out at two intensive care units in Paris over a two-year period. It included 42 participants with outof-hospital cardiac arrest of presumed cardiac cause, ventricular fibrillation or asystole as first cardiac rhythm, who were comatose after resuscitation. The mean age of participants was 52 to 56 years, and $19 \%$ were female. After admission, participants were randomly assigned to receive (1) high-flow haemofiltration, (2) high-flow haemofiltration plus therapeutic hypothermia or (3) standard therapy without hypothermia. The target temperature of the intervention group was $32^{\circ} \mathrm{C}$ to $34^{\circ} \mathrm{C}$, which should be maintained over a period of 24 hours; this was followed by a passive rewarming phase over 12 hours. Outcome parameters were survival, neurological outcome and adverse events. For this study, haemofiltration circuits, catheters and replacement fluid concentrates were provided by GAMBRO (GAMBRO).

Mori 2000 was published as an abstract with additional information provided by study authors. It was carried out at a University hospital in Sapporo, Japan, and included 54 participants with outof-hospital cardiac arrest with a Glasgow Coma Scale (GCS) score less than eight after resuscitation. After admission, participants were randomly assigned to receive (1) therapeutic hypothermia by water-circulating blankets above and below the participant with another ice mounted blanket over the participant, or (2) standard therapy without hypothermia. The target temperature of the intervention group was $32^{\circ} \mathrm{C}$ to $34^{\circ} \mathrm{C}$, which should be maintained over a period of three days. The reported outcome parameter was neurological outcome. Study authors provided no information on funding.

Nielsen 2013, which was published recently, was carried out at 36 intensive care units (ICUs) in Europe and Australia over a three-year period. It included 950 adults with out-of-hospital cardiac arrest of presumed cardiac cause and sustained return of spontaneous circulation who were comatose after resuscitation (GCS $<8)$. The mean age of participants was 64 years, and 19\% were female. After admission, participants were randomly assigned to receive (1) temperature management at $33^{\circ} \mathrm{C}$ (method of choice was up to the discretion of treating physicians), or (2) temperature management at $36^{\circ} \mathrm{C}$ (method of choice was up to the discretion of treating physicians). The target temperature of the intervention group was $32^{\circ} \mathrm{C}$ to $34^{\circ} \mathrm{C}$, which should be maintained over a period of 24 hours; this was followed by a rewarming phase over eight hours. Outcome parameters were survival and neurological and functional outcomes. Funding was provided by the Swedish HeartLung Foundation and others.

\section{Clinical heterogeneity}

We identified clinical heterogeneity due to cooling methods. In contrast to the other studies, Laurent 2005 used haemofiltration as the mode of cooling, which is substantially different from the standard cooling methods used in the other RCTs; therefore, we did not pool data with those from remaining studies. We now successfully contacted Kazuhisa Mori and Eric Dickson, who provided relevant details of their study (Mori 2000). On the basis of cooling methods and clinical characteristics, the remaining four studies appeared appropriate for pooling in the main analysis (Bernard 2002; HACA 2002; Hachimi-Idrissi 2001; Mori 2000).

\section{Excluded studies}

We excluded three studies; one was a substudy to the Nielsen 2013 trial that provided no extra information relevant to our review (CAEP/ACMU 2013), and for two, inclusion criteria for the intervention or control group did not apply (Lopez-de-Sa 2012; Takeda 2009) (see Characteristics of excluded studies).

\section{Ongoing studies}

We identified no ongoing studies.

\section{Awaiting classification}

No studies are awaiting classification.

\section{Risk of bias in included studies}

We assessed each included trial by using the following criteria: mode of randomization, allocation concealment, level of blinding, loss to follow-up, comparability of groups and use of measures to account for differences between groups (see Characteristics of included studies; Figure 2; and Figure 3). Risk of bias in the included studies was generally low, with relevant deficits noted in three out of six studies. 
Figure 2. Risk of bias graph: review authors' judgements about each risk of bias item presented as percentages across all included studies.

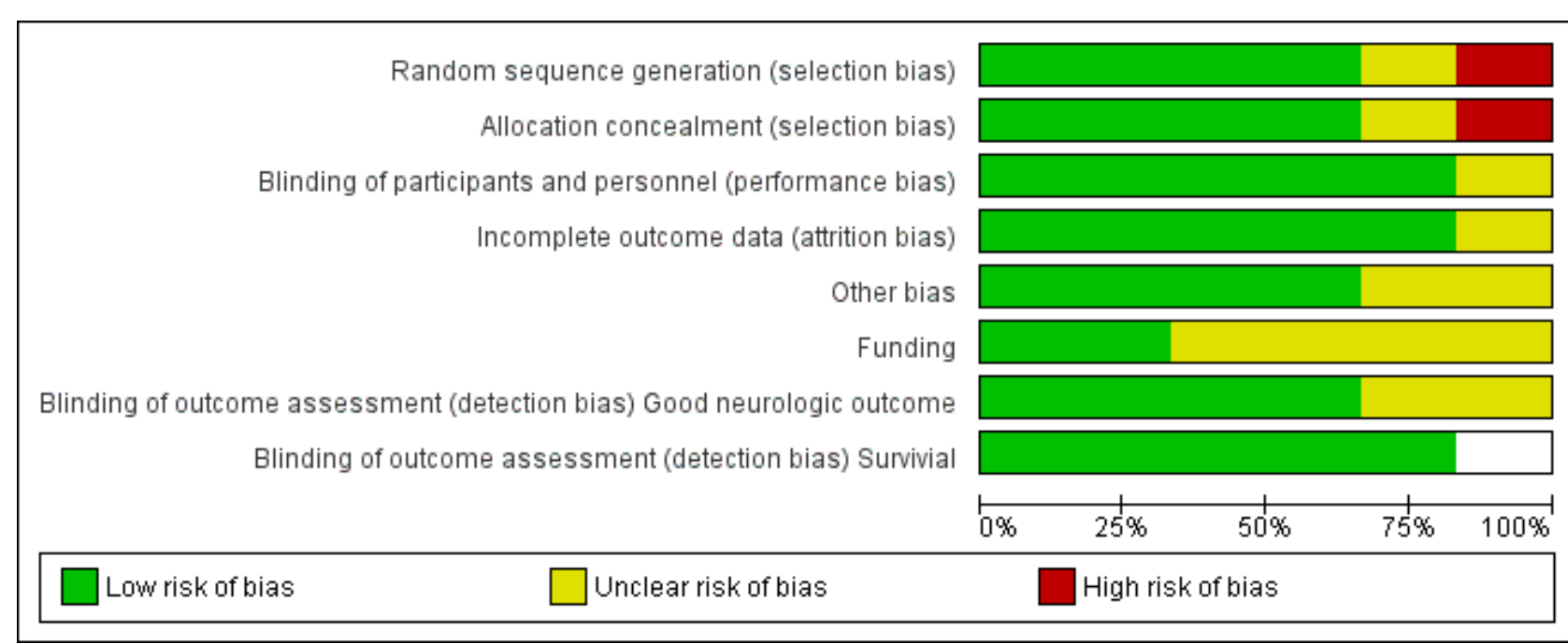


Figure 3. Risk of bias summary: review authors' judgements about each risk of bias item for each included study.

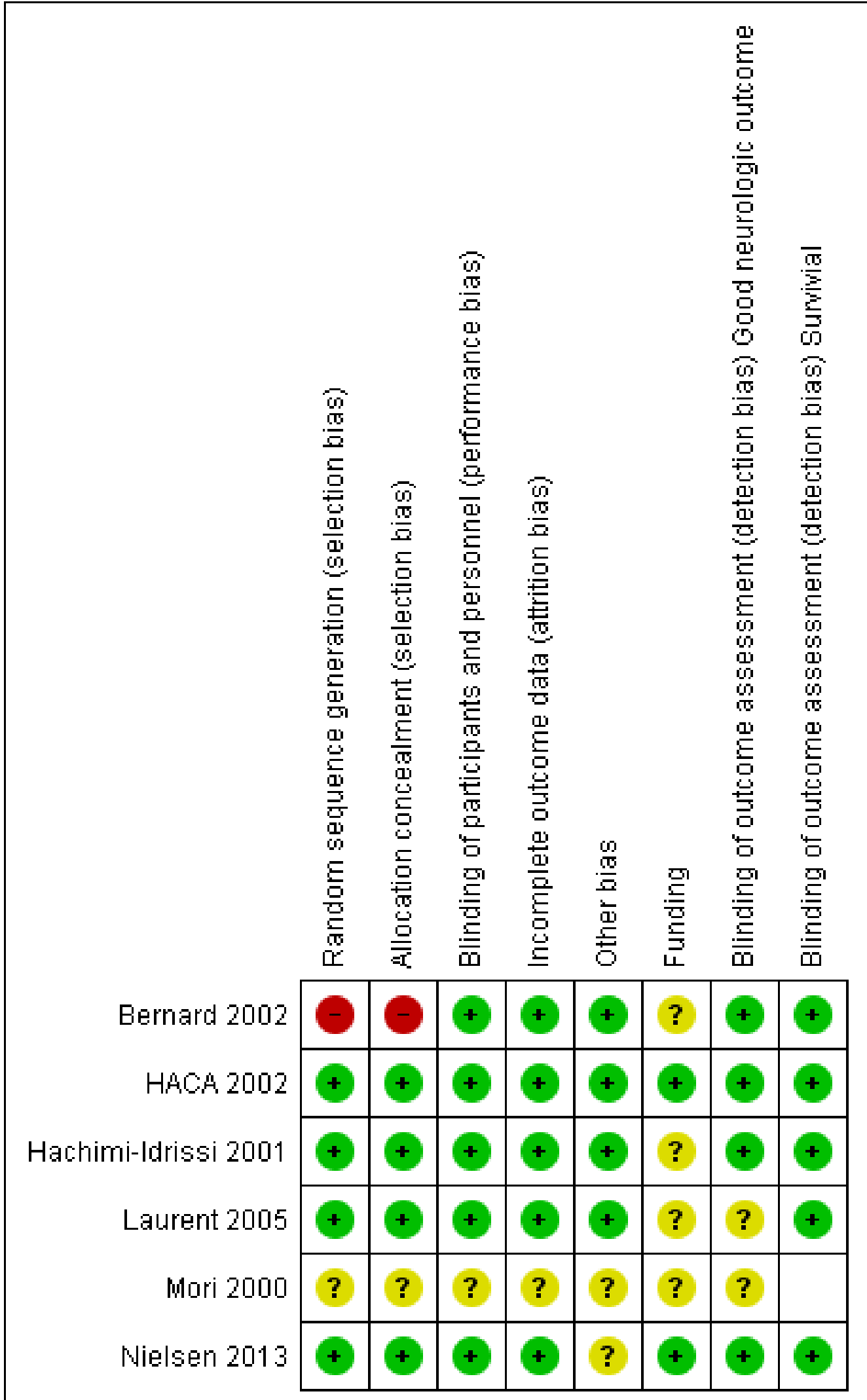


Figure 3. (Continued)

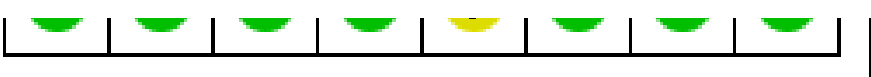

Except for the abstract (Mori 2000), all studies reported on almost all essential quality criteria, and loss to follow-up was within an acceptable range. One study showed deficits in the randomization process and adjustments made for inequalities in baseline characteristics between treatment and control groups (Bernard 2002). Follow-up was generally good in the included studies. In HACA 2002, hypothermia was discontinued in 14 participants because of death, arrhythmia, haemodynamic instability and technical problems with the cooling device;in one case because of liver rupture; in another because a randomly assigned participant had already been included in the study before cooling, and in another case because of an error in the duration of cooling. These participants were included in the intention-to-treat analysis of primary and secondary outcomes.

\section{Allocation}

Three trials (HACA 2002; Hachimi-Idrissi 2001; Laurent 2005) reported adequate randomization methods and use of opaque envelopes to conceal treatment allocation.

\section{Blinding}

Three trials reported blinded outcome assessment (Bernard 2002; HACA 2002; Hachimi-Idrissi 2001).

\section{Incomplete outcome data}

One study lost information on two participants for the primary endpoint (HACA 2002). All other studies reported complete followup.

\section{Selective reporting}

We found no indication of selective outcome reporting.

\section{Other potential sources of bias}

In two studies, treatment and control groups did not differ significantly in terms of reported baseline characteristics (HachimiIdrissi 2001; Laurent 2005), although Hachimi-Idrissi 2001 included rather small groups.

HACA 2002 described baseline differences between groups. Participants in the normothermia group were more likely to have a history of diabetes mellitus or coronary heart disease, and to have received basic life support from a bystander, than were those in the hypothermia group. Study authors adjusted for all baseline variables, and the risk ratio increased slightly, from $1.40(95 \% \mathrm{Cl}$ 1.08 to 1.81 ) to 1.47 (95\% Cl 1.09 to 1.82$)$.

Bernard 2002 reported differences in sex and rate of bystander cardiopulmonary resuscitation between groups but did not adjust for this possible bias.

Mori 2000 provided no information on baseline characteristics of participant groups.

\section{Effects of interventions}

See: Summary of findings for the main comparison Neurological outcome, survival and adverse events: conventional cooling compared with no cooling and $36^{\circ} \mathrm{C}$ for neuroprotection and survival in adults after cardiopulmonary resuscitation

\section{Primary outcome}

\section{Good neurological outcome}

With four studies (Bernard 2002; HACA 2002; Hachimi-Idrissi 2001; Mori 2000) (437 participants) reporting on conventional cooling methods compared with no cooling, the pooled result showed a better neurological outcome for the conventional cooling group (RR $1.94,95 \% \mathrm{Cl} 1.18$ to $3.21 ;\left.\right|^{2}$ statistic $=47 \%$; see Figure 4; and Data and analyses). The quality of the evidence was moderate. We downgraded the quality of the evidence as the result of imprecision. One study included 42 participants undergoing haemofiltration after cardiac arrest (Laurent 2005); this introduced considerable clinical heterogeneity and prevented pooling with the studies described above. Cooling using haemofiltration did not result in a difference in good neurological outcome (RR 0.71 , $95 \% \mathrm{Cl} 0.32$ to 1.54 ; see Figure 4). The quality of the evidence was very low. We downgraded the quality of the evidence as the result of risk of bias, imprecision and indirectness. Another study evaluated the effects of conventional cooling versus targeted temperature management at $36^{\circ} \mathrm{C}$ (Nielsen 2013). Investigators (Nielsen 2013) noted no effects on neurological outcome if therapeutic hypothermia at $33^{\circ} \mathrm{C}$ was compared with temperature management at $36^{\circ} \mathrm{C}$ ( $\mathrm{RR} 0.97,95 \% \mathrm{Cl} 0.85$ to $1.11 ; 933$ participants; see Figure 4). The quality of the evidence was moderate. We downgraded the quality of the evidence for this single but large RCT as the result of indirectness. 
Figure 4. Forest plot of comparison: 1 Neurological outcome: therapeutic hypothermia versus no hypothermia, outcome: 1.1 All studies with subgroups.

\begin{tabular}{|c|c|c|c|c|c|c|c|c|c|}
\hline \multirow[b]{2}{*}{ Study or Subgroup } & \multicolumn{2}{|c|}{ cooling to $33^{\circ} \mathrm{C}$} & \multicolumn{2}{|c|}{ Control } & \multirow[b]{2}{*}{ Weight } & \multirow{2}{*}{$\begin{array}{c}\text { Risk Ratio } \\
\text { M-H, Random, } 95 \% \mathrm{Cl}\end{array}$} & \multirow{2}{*}{\multicolumn{2}{|c|}{$\begin{array}{c}\text { Risk Ratio } \\
\text { M-H, Random, } 95 \% \mathrm{Cl}\end{array}$}} & Risk of Bias \\
\hline & Events & Total & Events & Total & & & & & A B C D E F G H \\
\hline \multicolumn{10}{|c|}{ 1.1.1 Corventional cooling vs no cooling } \\
\hline Mori 2000 & 18 & 36 & 2 & 18 & $11.1 \%$ & $4.50[1.17,17.30]$ & & & ??????? \\
\hline Hachimi-Idrissi 2001 & 8 & 16 & 2 & 17 & $10.6 \%$ & $4.25[1.06,17.08]$ & & & $\odot \odot \odot \odot ๑ ? \oplus ૯$ \\
\hline HACA 2002 & 75 & 136 & 54 & 137 & $48.9 \%$ & $1.40[1.08,1.81]$ & & & \\
\hline Bernard 2002 & 21 & 43 & 9 & 34 & $29.4 \%$ & $1.84[0.97,3.49]$ & & & \\
\hline Subtotal $(95 \% \mathrm{Cl})$ & & 231 & & 206 & $100.0 \%$ & $1.94[1.18,3.21]$ & & & \\
\hline Total events & 122 & & 67 & & & & & & \\
\hline \multicolumn{10}{|c|}{$\begin{array}{l}\text { Heterogeneity: } \text { Tau }^{2}=0.12 ; \mathrm{Chi}^{2}=5.70, \mathrm{df}=3(P=0.13) ; \mathrm{I}^{2}=47 \% \\
\text { Test for overall effect: } Z=2.60(P=0.009)\end{array}$} \\
\hline \multicolumn{10}{|c|}{ 1.1.2 Corventional cooling vs $36^{\circ}$ temperature management } \\
\hline $\begin{array}{l}\text { Nielsen } 2013 \\
\text { Subtotal }(95 \% \mathrm{Cl})\end{array}$ & 218 & $\begin{array}{l}469 \\
469\end{array}$ & 222 & $\begin{array}{l}464 \\
464\end{array}$ & $\begin{array}{l}100.0 \% \\
100.0 \%\end{array}$ & $0.97[0.85,1.11]$ & & & $\odot \odot \odot \odot ? \odot \odot \odot ~$ \\
\hline Total events & 218 & & 222 & & & & & & \\
\hline \multicolumn{10}{|c|}{ Heterogeneity: Not applicable } \\
\hline \multicolumn{10}{|c|}{ Test for overall effect: $Z=0.42(P=0.68)$} \\
\hline \multicolumn{10}{|c|}{ 1.1.3 Cooling with haemofiltration vs no cooling } \\
\hline Laurent 2005 & 7 & 22 & 9 & 20 & $100.0 \%$ & $0.71[0.32,1.54]$ & & & $\odot \odot \odot \odot \odot ? ? ?$ \\
\hline Total events & 7 & & $\mathrm{~g}$ & & $100.0 \%$ & $0.71[0.32,1.54]$ & & & \\
\hline \multirow{3}{*}{\multicolumn{10}{|c|}{$\begin{array}{l}\text { Heterogeneity: Not applicable } \\
\text { Test for overall effect: } Z=0.87(P=0.38)\end{array}$}} \\
\hline & & & & & & & & & \\
\hline & & & & & & & & & \\
\hline & & & & & & & 0.20 .5 & $\begin{array}{lll}1 & 2 & 5\end{array}$ & \\
\hline \multicolumn{10}{|c|}{ Test for subgroup differences: $\mathrm{Chi}^{2}=7.65, \mathrm{df}=2(\mathrm{P}=0.02), \mathrm{I}^{2}=73.9 \%$} \\
\hline \multicolumn{10}{|c|}{ Risk of bias legend } \\
\hline \multicolumn{10}{|c|}{ (A) Random sequence generation (selection bias) } \\
\hline \multicolumn{10}{|c|}{ (B) Allocation concealment (selection bias) } \\
\hline \multicolumn{10}{|c|}{ (C) Blinding of participants and personnel (performance bias) } \\
\hline \multicolumn{10}{|c|}{ (D) Incomplete outcome data (attrition bias) } \\
\hline \multicolumn{10}{|c|}{ (E) Other bias } \\
\hline \multicolumn{10}{|c|}{ (F) Funding } \\
\hline \multicolumn{10}{|c|}{ (G) Blinding of outcome assessment (detection bias) Good neurologic outcome } \\
\hline (H) Blinding of outcom & assessm & & ction bias & ) Surviv & & & & & \\
\hline
\end{tabular}

When data from all studies that used conventional cooling methods regardless of the control treatment (Bernard 2002; HACA 2002; Hachimi-Idrissi 2001; Mori 2000; Nielsen 2013) were pooled, cooling to $33^{\circ} \mathrm{C}$ was still superior to no cooling or temperature management at $36^{\circ} \mathrm{C}$ (RR 1.53, 95\% Cl 1.02 to 2.29; $\mathrm{P}$ value $=0.04$; see Figure 5). However, we found considerable heterogeneity when pooling all of these studies (heterogeneity: $\mathrm{tau}^{2}=0.12 ; \mathrm{Chi}^{2}=17.28 ; \mathrm{df}=4$ $(P$ value $=0.002) ; I^{2}$ statistic $\left.=77 \%\right)$, possibly because a different control group treatment was given in one study (Nielsen 2013). The test for subgroup differences according to control group treatment (no cooling vs target temperature at $36^{\circ} \mathrm{C}$ ) was highly positive $\left(\mathrm{Chi}^{2}\right.$ $=6.84 ; \mathrm{df}=1(\mathrm{P}$ value $=0.009))$. Cautious interpretation of this effect is therefore warranted, but to inform the current discussion, we present the pooled estimate for the primary outcome despite obvious limitations here and restrict the summary of findings to findings with the least ambiguity (Summary of findings for the main comparison). 


\section{Publication bias}

Currently, identified studies are too few to permit inferences from funnel plots; therefore, we have not presented them in the latest version of this review.

\section{Secondary outcomes}

\section{Survival to hospital discharge and at six months}

With three studies (Bernard 2002; HACA 2002; Hachimi-Idrissi $2001 ; 383$ participants) reporting on conventional cooling methods compared with no cooling, the pooled result showed benefit for survival for the conventional cooling group (RR 1.35, 95\% Cl 1.10 to $1.65 ; 1^{2}$ statistic $=0 \%$; see Figure 6 ; and Data and analyses). The quality of the evidence was moderate. We downgraded the quality of the evidence as the result of imprecision. One study included 42 participants undergoing haemofiltration after cardiac arrest (Laurent 2005), which introduced considerable clinical heterogeneity and prevented pooling of data with those of the studies described above. Cooling using haemofiltration did not result in differences in survival (RR $0.71,95 \% \mathrm{Cl} 0.32$ to 1.54 ; see Figure 6). The quality of the evidence was very low. We downgraded the quality of the evidence as the result of risk of bias, imprecision and indirectness. Another study (Nielsen 2013) evaluated effects of conventional cooling versus targeted temperature management at $36^{\circ} \mathrm{C}$ and reported no effects on survival when therapeutic hypothermia at $33^{\circ} \mathrm{C}$ was compared with temperature management at $36^{\circ} \mathrm{C}(\mathrm{RR} 0.97,95 \% \mathrm{Cl} 0.86$ to 1.10 ; 939 participants; see Figure 6). The quality of the evidence was moderate. We downgraded the quality of the evidence for this single but large RCT as the result of indirectness.

Figure 6. Forest plot of comparison: 3 Survival: therapeutic hypothermia versus no hypothermia, outcome: 3.1 All studies with subgroups.

\begin{tabular}{|c|c|c|c|c|c|c|c|c|}
\hline \multirow[b]{2}{*}{ Study or Subgroup } & \multicolumn{2}{|c|}{ cooling to $33^{\circ} \mathrm{C}$} & \multicolumn{2}{|c|}{ Control } & \multirow[b]{2}{*}{ Weight } & \multirow{2}{*}{$\begin{array}{c}\text { Risk Ratio } \\
\text { M-H, Fixed, } 95 \% \mathrm{Cl}\end{array}$} & \multirow{2}{*}{\multicolumn{2}{|c|}{$\begin{array}{c}\text { Risk Ratio } \\
\text { M-H, Fixed, 95\% Cl }\end{array}$}} \\
\hline & Events & Total & Events & Total & & & & \\
\hline \multicolumn{9}{|c|}{ 2.1.1 Corventional cooling vs no cooling } \\
\hline Hachimi-Idrissi 2001 & 4 & 16 & 1 & 17 & $1.2 \%$ & $4.25[0.53,34.10]$ & & \\
\hline HACA 2002 & 85 & 136 & 67 & 137 & $83.4 \%$ & $1.28[1.03,1.58]$ & & \\
\hline Bernard 2002 & 21 & 43 & 11 & 34 & $15.4 \%$ & $1.51[0.85,2.68]$ & & \\
\hline Subtotal $(95 \% \mathrm{Cl})$ & & 195 & & 188 & $100.0 \%$ & $1.35[1.10,1.65]$ & & \\
\hline Total events & 110 & & 79 & & & & & \\
\hline \multicolumn{9}{|c|}{ Heterogeneity: $\mathrm{Ch}^{2}=1.56, \mathrm{df}=2(\mathrm{P}=0.46) ;\left.\right|^{2}=0 \%$} \\
\hline \multicolumn{9}{|c|}{ 2.1.2 Corventional cooling vs $36^{\circ}$ temperature management } \\
\hline Nielsen 2013 & 238 & 473 & 241 & 466 & $100.0 \%$ & $0.97[0.86,1.10]$ & & \\
\hline Subtotal $(95 \% \mathrm{Cl})$ & & 473 & & 466 & $100.0 \%$ & $0.97[0.86,1.10]$ & & \\
\hline Total events & 238 & & 241 & & & & & \\
\hline \multicolumn{9}{|c|}{ Heterogeneity: Not applicable } \\
\hline \multicolumn{9}{|c|}{ Test for overall effect: $Z=0.43(P=0.67)$} \\
\hline \multicolumn{9}{|c|}{ 2.1.3 Cooling with haemofiltration vs no cooling } \\
\hline Laurent 2005 & 7 & 22 & 9 & 20 & $100.0 \%$ & $0.71[0.32,1.54]$ & & \\
\hline Subtotal $(95 \% \mathrm{Cl})$ & & 22 & & 20 & $100.0 \%$ & $0.71[0.32,1.54]$ & & \\
\hline Total events & 7 & & 9 & & & & & \\
\hline \multirow{2}{*}{\multicolumn{9}{|c|}{$\begin{array}{l}\text { Heterogeneity: Not applicable } \\
\text { Test for overall effect: } Z=0.87(P=0.38)\end{array}$}} \\
\hline & & & & & & & & \\
\hline & & & & & & & $\begin{array}{lll}1 & 1 & 1 \\
0.2 & 0.5 & 1\end{array}$ & $\begin{array}{ll}1 & 1 \\
2 & 5\end{array}$ \\
\hline \multicolumn{9}{|c|}{ Test for subgroup differences: $\mathrm{Chi}^{2}=8.27, \mathrm{df}=2(\mathrm{P}=0.02) \mathrm{I}^{2}=75.8 \%$} \\
\hline \multicolumn{9}{|c|}{$\begin{array}{l}\text { Risk of bias legend } \\
\text { lest }\end{array}$} \\
\hline \multicolumn{9}{|c|}{ (A) Random sequence generation (selection bias) } \\
\hline \multicolumn{9}{|c|}{ (B) Allocation concealment (selection bias) } \\
\hline \multicolumn{9}{|c|}{ (C) Blinding of participants and personnel (performance bias) } \\
\hline \multicolumn{9}{|c|}{ (D) Incomplete outcome data (attrition bias) } \\
\hline \multicolumn{9}{|c|}{ (E) Other bias } \\
\hline \multicolumn{9}{|c|}{ (F) Funding } \\
\hline \multicolumn{9}{|c|}{ (G) Blinding of outcome assessment (detection bias) Good neurologic outcome } \\
\hline (H) Blinding of outcon & assessm & t (dete & ction bias & Survi & & & & \\
\hline
\end{tabular}
A B C D E F G H $++\odot+?+\div$ (2) $\odot \odot \odot+? \odot+$
When all studies that used conventional cooling methods regardless of the control treatment (Bernard 2002; HACA 2002; Hachimi-Idrissi 2001; Nielsen 2013) were pooled, we noted no survival benefit (RR $1.07,95 \% \mathrm{Cl} 0.96$ to 1.19 ; see Figure 7 ). We found considerable heterogeneity when pooling these studies, possibly because a different control group treatment was given in one study (Nielsen 2013). The test for subgroup differences according to control group treatment (no cooling vs target temperature at $36^{\circ} \mathrm{C}$ ) was highly positive $\left(\mathrm{Chi}^{2}=6.36, \mathrm{df}=1(\mathrm{P}\right.$ value $\left.=0.01)\right)$. Cautious interpretation of this effect is therefore warranted, but to inform the current discussion, we present the pooled estimate for the primary outcome despite obvious limitations. We restricted the summary of findings to findings with the least ambiguity (Summary of findings for the main comparison). 
Figure 7. Forest plot of comparison: 3 Survival: therapeutic hypothermia versus no hypothermia, outcome: 3.2 Conventional cooling.

\begin{tabular}{|c|c|c|c|c|c|c|c|c|c|}
\hline \multirow[b]{2}{*}{ Study or Subgroup } & \multicolumn{2}{|c|}{ cooling to $33^{\circ} \mathrm{C}$} & \multicolumn{2}{|c|}{ Control } & \multirow{2}{*}{ Weight } & \multirow{2}{*}{$\begin{array}{c}\text { Risk Ratio } \\
\text { M-H, Fixed, 95\% Cl }\end{array}$} & \multirow{2}{*}{\multicolumn{2}{|c|}{$\begin{array}{c}\text { Risk Ratio } \\
\text { M-H, Fixed, 95\% Cl }\end{array}$}} & Risk of Bias \\
\hline & Events & Total & Events & Total & & & & & A B C D E F G H \\
\hline \multicolumn{10}{|c|}{ 2.2.1 Corventional cooling vs no cooling } \\
\hline Hachimi-Idrissi 2001 & 4 & 16 & 1 & 17 & $0.3 \%$ & $4.25[0.53,34.10]$ & & & $\bullet \odot \odot \oplus \odot ? \oplus \oplus$ \\
\hline HACA 2002 & 85 & 136 & 67 & 137 & $20.7 \%$ & $1.28[1.03,1.58]$ & & & \\
\hline Bernard 2002 & 21 & 43 & 11 & 34 & $3.8 \%$ & $1.51[0.85,2.68]$ & & & \\
\hline Subtotal $(95 \% \mathrm{Cl})$ & & 195 & & 188 & $24.8 \%$ & $1.35[1.10,1.65]$ & & & \\
\hline Total events & 110 & & 79 & & & & & & \\
\hline \multirow{2}{*}{\multicolumn{10}{|c|}{$\begin{array}{l}\text { Heterogeneity: } \mathrm{Chi}^{2}=1.56, \mathrm{df}=2(\mathrm{P}=0.46) ; \mathrm{I}^{2}=0 \% \\
\text { Test for overall effect: } Z=2.90(P=0.004)\end{array}$}} \\
\hline & & & & & & & & & \\
\hline \multicolumn{10}{|c|}{ 2.2.2 Corventional cooling vs $36^{\circ}$ temperature management } \\
\hline Nielsen 2013 & 238 & 473 & 241 & 466 & $75.2 \%$ & $0.97[0.86,1.10]$ & & & $\oplus \odot \odot \oplus ? \oplus \odot \oplus$ \\
\hline Subtotal $(95 \% \mathrm{Cl})$ & & 473 & & 466 & $75.2 \%$ & $0.97[0.86,1.10]$ & & & \\
\hline Total events & 238 & & 241 & & & & & & \\
\hline \multirow{2}{*}{\multicolumn{10}{|c|}{$\begin{array}{l}\text { Heterogeneity: Not applicable } \\
\text { Test for overall effect: } Z=0.43(P=0.67)\end{array}$}} \\
\hline & & & & & & & & & \\
\hline Total $(95 \% \mathrm{Cl})$ & & 668 & & 654 & $100.0 \%$ & $1.07[0.96,1.19]$ & & 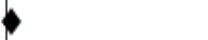 & \\
\hline Total events & 348 & & 320 & & & & & & \\
\hline \multirow{3}{*}{\multicolumn{7}{|c|}{$\begin{array}{l}\text { Heterogeneity: } \mathrm{Ch}^{2}=7.88, \mathrm{df}=3(\mathrm{P}=0.05) ; \mathrm{I}^{2}=62 \% \\
\text { Test for overall effect: } \mathrm{Z}=1.18(\mathrm{P}=0.24) \\
\text { Test for subgroup differences: } \mathrm{Ch}^{2}=7.23, \mathrm{df}=1(\mathrm{P}=0.007) \mathrm{I}^{2}=86.2 \%\end{array}$}} & $\begin{array}{ll}1 & 0.2 \\
\end{array}$ & $\begin{array}{ll} & 1 \\
2 & 5\end{array}$ & \\
\hline & & & & & & & $\begin{array}{l}0.2 \\
\text { Favours control }\end{array}$ & $12 \frac{5}{2} \quad 5$ & \\
\hline & & & & & & & & & \\
\hline \multicolumn{10}{|c|}{ Risk of bias legend } \\
\hline \multicolumn{10}{|c|}{ (A) Random sequence generation (selection bias) } \\
\hline \multicolumn{10}{|c|}{ (B) Allocation concealment (selection bias) } \\
\hline \multicolumn{10}{|c|}{ (C) Blinding of participants and personnel (performance bias) } \\
\hline \multicolumn{10}{|c|}{ (D) Incomplete outcome data (attrition bias) } \\
\hline \multicolumn{10}{|c|}{ (E) Other bias } \\
\hline \multicolumn{10}{|c|}{ (F) Funding } \\
\hline \multicolumn{10}{|c|}{ (G) Blinding of outcome assessment (detection bias) Good neurologic outcome } \\
\hline (H) Blinding of outcom & assessm & & tion hio & Survi & & & & & \\
\hline
\end{tabular}

\section{Long term survival}

We found no data on this outcome.

\section{Quality of life at six months and long term}

We found no data on this outcome.

\section{Dependency}

Nielsen 2013 reported on the modified Rankin Scale at six months (RR 1.01, 95\% $\mathrm{Cl} 0.89$ to 1.14; P value $=0.87$ ). We found no additional data on this outcome.

\section{Cost-effectiveness}

We found no data on this outcome.

\section{Adverse events}

We included in the analysis all trials that reported on adverse events, regardless of heterogeneity. The following adverse events were reported in five studies (Bernard 2002; HACA 2002; HachimiIdrissi 2001; Laurent 2005; Nielsen 2013; 1358 participants): bleeding of any severity and at various locations, need for platelet transfusions, pneumonia, sepsis, pancreatitis, renal failure or oliguria, haemodialysis, pulmonary oedema, seizures, atrial fibrillation/flutter, lethal or long-lasting arrhythmias, cardiac complications and electrolyte and metabolic imbalances (see Table 3).

Two studies with 1205 participants (HACA 2002; Nielsen 2013) reported pneumonia, which was more frequent in the treatment group (RR 1.15, 95\% Cl 1.02 to 1.30; see Summary of findings for the main comparison). The quality of the evidence was moderate. We downgraded the quality of the evidence as the result of indirectness (differences in control groups - no temperature management and $36^{\circ} \mathrm{C}$ ). Hypokalaemia was reported in two studies (Laurent 2005; Nielsen 2013) including 975 participants and was more frequent in the intervention group (RR $1.38,95 \%$ C 1.03 to 1.84). The quality of the evidence was low. We downgraded the quality of the evidence as the result of very serious indirectness (differences in intervention - conventional cooling and haemofiltration - and control groups). Otherwise, researchers observed no significant differences between groups.

\section{DISCUSSION}

\section{Summary of main results}

Evidence from five studies with 1370 participants contributing data to the primary outcomes of this review showed that therapeutic hypothermia with conventional cooling methods improved neurological outcome after cardiac arrest. The impact on survival was less certain, but a strong effect was evident when therapeutic hypothermia was compared with no temperature management.

\section{Overall completeness and applicability of evidence}

All studies reported on the same outcomes and, except for Mori 2000 , for which we did not receive further information, all outcome assessors were blinded to treatment (Bernard 2002; HACA 2002; Hachimi-Idrissi 2001; Laurent 2005; Nielsen 2013). The cerebral performance category $(\mathrm{CPC})$ is well standardized and easy to 
measure, and gives a crude approximation of the person's ability to perform tasks of daily life. One of its limitations is lack of accuracy when it comes to estimating cognitive functions and personal and social impact of cardiac arrest.

After completing our literature search, we were able to include individual patient data (IPD) for only three out of five eligible studies retrieved (Bernard 2002; HACA 2002; Hachimi-Idrissi 2001). Therefore, we had to omit the IPD analysis and could calculate only subgroup analyses using available data. Subsequently, precision in the subsets of participants was humble and maybe was too low to permit firm conclusions about the subgroups.

One of the challenges of this review was heterogeneity at the study level. In the case of Laurent 2005, the two treatment modalities (mild therapeutic hypothermia with and without haemodialysis) were clinically too heterogeneous to be combined with those of other studies. As mentioned in the Background section, one of the theories of the beneficial effects of cooling deals with attenuation of the effects of free radicals and other mediators. Haemofiltration may act in a similar way, by reducing the number of free radicals. This effect is likely to interact with the effect of therapeutic hypothermia.

Control group treatment is another important driver for heterogeneity. Nielsen 2013 differed considerably in terms of control group treatment, as investigators used a target temperature of $36^{\circ} \mathrm{C}$ in contrast to no temperature management as employed by the other studies. Despite seemingly subtle differences, this can be expressed as two distinct clinical questions: 'Does mild therapeutic hypothermia compared with no mild therapeutic hypothermia at all influence outcome?' versus 'Does temperature management targeted to $33^{\circ} \mathrm{C}$ compared with $36^{\circ} \mathrm{C}$ influence outcome?' These questions were often ignored in clinical discussions, however. To meet concerns of heterogeneity and at the same time give a better picture of available data, we decided to perform an ancillary analysis. Without temperature management in the control group, therapeutic hypothermia at $32^{\circ} \mathrm{C}$ to $34^{\circ} \mathrm{C}$ improves neurological outcome after cardiac arrest, and this effect persists when the control group receives active temperature management at $36^{\circ} \mathrm{C}$. Whether $36^{\circ} \mathrm{C}$, cooling to $32^{\circ} \mathrm{C}$ to $34^{\circ} \mathrm{C}$ and no cooling are equally effective can be judged only by an indirect comparison. This indirect comparison however should be performed when a sufficient degree of transitivity is present, which is not necessarily the case here (Storm 2014; Stub 2014).

In our sensitivity analysis, the effect was robust against allocation concealment and model choice.

Many cooling methods are available, ranging from expensive device-controlled methods to very cheap cold fluids and ice packs. Proof of superiority of any cooling method above others is still lacking.

After publication of the two RCTs on therapeutic hypothermia (Bernard 2002; HACA 2002), guidelines were published by the International Liaison Committee on Resuscitation (ILCOR) on the application of therapeutic hypothermia after cardiac arrest (Nolan 2003). The publication of the Targeted Temperature Management (TTM) trial (Nielsen 2013) has led to ongoing discussion about optimal levels of target temperature. In their most recent statement, ILCOR members have advised that "Pending formal consensus on the optimal temperature, we suggest that clinicians provide post-resuscitation care based on the current treatment recommendations. We accept that some clinicians may make a local decision to use a target temperature of $36^{\circ} \mathrm{C}$ pending this further guidance." Similar up-to-date guidelines of the European Resuscitation Council state the following: "Targeted temperature management remains important but there is now an option to target a temperature of $36^{\circ} \mathrm{C}$ instead of the previously recommended 32 to $34^{\circ} \mathrm{C}$ " (Soar 2015), and the American Heart Association provides this advice: "We recommend selecting and maintaining a constant target temperature between $32^{\circ} \mathrm{C}$ and $36^{\circ} \mathrm{C}$ for those patients in whom temperature control is used (strong recommendation, moderate quality evidence)" (Callaway 2015).

Investigators have observed that pyrexia after the cooling period is associated with increased mortality and unfavourable neurological outcome (Bro-Jeppesen 2013; Leary 2013; Zeiner 2001). Mean body temperature 12 hours after the start of cooling in the 'normothermia group' was around $37.6^{\circ} \mathrm{C}$ in HACA 2002 and $37.4^{\circ} \mathrm{C}$ in Bernard 2002. Hachimi-Idrissi 2001 did not report the body temperature of the control group. Adding results of Nielsen 2013 slightly reduced the effect size, but $33^{\circ} \mathrm{C}$ in comparison with higher temperatures still showed a significant and relevant beneficial effect for neurological outcome. A dose-response effect over different levels of hypothermia is possible, but studies are still too few to prove this.

\section{Quality of the evidence}

Risk of bias was low for most studies and when present did not strongly influence the estimates. Therefore, we considered the results robust against risk of bias from within the studies, and this was confirmed by our sensitivity analysis.

We downgraded the quality of evidence to moderate for main outcomes, mainly as the result of imprecision, as the number of events fell below the limit of the suggested optimal information size (Guyatt 2011).

We graded indirectness as not relevant for the main analysis of our review because it reflects common practice. Furthermore, 90\% (in HACA 2002) and 92\% (in Bernard 2002) of all eligible participants were randomly assigned. In Laurent 2005 and Hachimi-Idrissi 2001, inclusion of all eligible participants was reported. Generally, participants within the included studies appeared to be treated according to international guidelines. Indirectness, however, was an issue for the analysis of adverse events, for which we pooled all available studies regardless of differences in intervention and control group treatments.

The included studies represent a mixture of efficacy studies and one larger pragmatic study (Nielsen 2013). All studies were academia initiated.

\section{Potential biases in the review process}

One of the problems involved with merging the data for this review was the difference in inclusion criteria. Generally, among all participants resuscitated and brought to hospital, between $18 \%$ and $42 \%$ have non-witnessed arrests, only $30 \%$ to $58 \%$ have a confirmed ventricular fibrillation (VF) rhythm as first rhythm (Haukoos 2004; Herlitz 2003a; Kim 2001) and 40\% are resuscitated in-hospital. In this review, the two larger studies with available IPD included only participants with a cardiac cause of cardiac arrest, and with VF or ventricular tachycardia (VT) rhythm as the 
first cardiac rhythm (Bernard 2002; HACA 2002). Most participants had an out-of-hospital cardiac arrest. From the pathogenesis of global cerebral ischaemias and theories as to why therapeutic hypothermia is effective, we could find no reason why therapeutic hypothermia should not be as effective in participants with asystole as the first cardiac rhythm or in those with non-cardiac causes for cardiac arrest. In a meta-analysis (Holzer 2005), the effect of therapeutic hypothermia was only sightly changed by baseline variables. A retrospective cohort study showed that the effect of therapeutic hypothermia was independent of various confounders, including cardiac arrest conditions (Arrich 2006).

The trial by Mori 2000 and colleagues was published as an abstract. In personal communications, we were able to receive information about the cooling method but not about quality criteria for this randomized controlled trial. Therefore, we have rated most of the quality criteria in our risk of bias assessment as 'unclear'.

The most recent study (Nielsen 2013) was the largest one in this field of research. Adding these data introduced considerable heterogeneity, which we had not observed with the existing studies. A clinical viewpoint suggests various reasons, the most obvious being the control group, which was kept at $36^{\circ} \mathrm{C}$ and not 'no cooling' as in other studies. The design of Nielsen 2013 was a pragmatic one (multi-centre, different methods of cooling, etc.), which may not be suitable as long as the cooling 'dose', which is mainly target temperature and cooling duration, is not unequivocally characterized in proof of concept studies. Additionally, Nielsen 2013 had a very short duration from collapse to resuscitation (one minute) compared with the other trials (around 10 minutes). Reports show that the effect of therapeutic hypothermia depends strongly on this no flow time (Testori 2012). Knowing whether the results of this study should be added to existing data, especially as they caused a high level of heterogeneity, was challenging. To provide the most informative picture of all levels of hypothermia, we have decided to present an ancillary analysis at the study level. Despite controversial arguments against and for pooling of all studies, a beneficial and statistically significant effect on neurological outcome was seen when all studies on conventional cooling were pooled (RR 1.53, 95\% $\mathrm{Cl} 1.02$ to 2.29 ).

For the subgroup of participants with non-witnessed arrests, we observed an effect size substantially greater than the pooled summary effect (RR 5.31, 95\% Cl 1.40 to 20.21) (Table 1). However, the group of non-witnessed arrests was small (22 participants only) and yielded large confidence intervals. Although it seems that participants benefited from the treatment provided, the result should be interpreted with caution.

\section{Agreements and disagreements with other studies or reviews}

We are aware of three other meta-analyses with similar objectives. The meta-analysis by Holzer 2005 is very similar to the one performed in our review method-wise and in many ways was a predecessor to the first version of this Cochrane review. We were able to include two additional studies (Laurent 2005; Mori 2000), but the main result is comparable. Another meta-analysis was published in 2011 (Nielsen 2011). The review authors judged the overall quality of the included studies to be at a lower level than we did in our review. From the available five studies, they combined four and five on the basis of a different judgement on clinical heterogeneity, and they provided a trial sequential analysis. The main findings were comparable between the two reviews, whereas their interpretation was more conservative than ours. We found a third meta-analysis published recently, which focused on the safety effects of therapeutic hypothermia (Xiao 2013). Upon pooling randomized and non-randomized studies, review authors found overall better survival with therapeutic hypothermia with a slightly elevated incidence of arrhythmia and hypokalaemia.

\section{AUTHORS' CONCLUSIONS}

\section{Implications for practice}

Moderate-quality evidence suggests that conventional cooling methods to induce mild therapeutic hypothermia improve neurological outcome after cardiac arrest, specifically if compared with no temperature management. Available evidence was derived from studies in which the target temperature was $34^{\circ} \mathrm{C}$ or lower. This is in line with current best medical practice as recommended by international resuscitation guidelines (Callaway 2015; Soar 2015) on using hypothermia/targeted temperature management for survivors of cardiac arrest. We had insufficient evidence to determine the effects of therapeutic hypothermia on participants with in-hospital cardiac arrest, asystole or non-cardiac causes of arrest.

\section{Implications for research}

A considerable knowledge gap for what constitutes an optimal cooling protocol is ongoing. Available clinical trials on therapeutic hypothermia comprise a variety of patient populations and modes of hypothermia. It remains specifically unclear what the ideal target temperature should be. Likewise, it is unclear for what period of time targeted temperature management should be maintained. Whether cooling should be initiated prehospital or inhospital needs further research. We expect that mild therapeutic hypothermia exerts its effects differently across subgroups of participants, but evidence is lacking. Evaluation of a possible doseresponse effect of therapeutic hypothermia would shed some light on an optimal treatment regimen with ample room for costeffectiveness analyses.

\section{ACKNOWLEDGEMENTS}

We would like to thank the editorial team and the peer reviewers of this updated review 2015 (Vibeke E Horstmann, Sheila Page, Rodrigo Cavallazzi and Jane Cracknell). 


\section{R E F E R E N C E S}

\section{References to studies included in this review}

Bernard 2002 \{published data only\}

* Bernard SA, Gray TW, Buist MD, Jones BM, Silvester W, Gutteridge $G$, et al. Treatment of comatose survivors of out-ofhospital cardiac arrest with induced hypothermia. New England Journal of Medicine 2002;346(8):557-63. [MEDLINE: 11856794]

\section{HACA 2002 \{published data only\}}

* Hypothermia after Cardiac Arrest Study Group. Mild therapeutic hypothermia to improve the neurologic outcome after cardiac arrest. New England Journal of Medicine 2002;346(8):549-56. [MEDLINE: 11856793]

Tiainen M, Kovala TT, Takkunen OS, Roine RO. Somatosensory and brainstem auditory evoked potentials in cardiac arrest patients treated with hypothermia. Critical Care Medicine 2005;33(8):1736-40. [PUBMED: 16096450]

Tiainen M, Poutiainen E, Kovala T, Takkunen O, Happola O, Roine RO. Cognitive and neurophysiological outcome of cardiac arrest survivors treated with therapeutic hypothermia. Stroke 2007;38(8):2303-8. [PUBMED: 17585081]

Tiainen M, Roine RO, Pettila V, Takkunen O. Serum neuronspecific enolase and S-100B protein in cardiac arrest patients treated with hypothermia. Stroke 2003;34(12):2881-6. [PUBMED: 14631087]

Hachimi-Idrissi 2001 \{published and unpublished data\}

* Hachimi-Idrissi S, Corne L, Ebinger G, Michotte Y, Huyghens L. Mild hypothermia induced by a helmet device: a clinical feasibility study. Resuscitation 2001;51(3):275-81. [MEDLINE: 11738778]

\section{Laurent 2005 \{published data only\}}

* Laurent I, Adrie C, Vinsonneau C, Cariou A, Chiche JD, Ohanessian A, et al. High-volume hemofiltration after out-ofhospital cardiac arrest: a randomized study. Journal of the American College of Cardiology 2005;46(3):432-7. [MEDLINE: 16053954]

\section{Mori 2000 \{published data only\}}

* Mori K, Takeyama Y, Itoh Y, Nara S, Yoshida M, Ura H, et al. A multivariate analysis of prognostic factors in survivors of outof-hospital cardiac arrest with brain hypothermia. Critical Care Medicine. 2000; Vol. 28:A168.

\section{Nielsen 2013 \{published data only\}}

CAEP/ACMU. 2013 CAEP/ACMU Scientific Abstracts, CAEP 2013 June 1-5, 2013, Vancouver, British Columbia. Canadian Journal of Emergency Medicine 2013;15:S1-S79. [Embase/Ovid Accession Number: 75003618$]$

* Nielsen N, Wetterslev J, Cronberg T, Erlinge D, Gasche Y, Hassager $\mathrm{C}$, et al. TTM Trial Investigators. Targeted temperature management at $33^{\circ} \mathrm{C}$ versus $36^{\circ} \mathrm{C}$ after cardiac arrest. New England Journal of Medicine 2013;369(23):2197-206. [PUBMED: 24237006]

\section{References to studies excluded from this review}

CAEP/ACMU 2013 \{published data only\}

CAEP/ACMU. 2013 CAEP/ACMU Scientific Abstracts, CAEP 2013

June 1-5, 2013, Vancouver, British Columbia. Canadian Journal of Emergency Medicine 2013;15:S1-S79. [Embase/Ovid Accession Number: 75003618]

\section{Lopez-de-Sa 2012 \{published data only\}}

Lopez-de-Sa E, Rey JR, Armada E, Salinas P, Viana-Tejedor A, Espinosa-Garcia $S$, et al. Hypothermia in comatose survivors from out-of-hospital cardiac arrest: pilot trial comparing 2 levels of target temperature. Circulation 2012;126(24):2826-33. [PUBMED: 23136160]

\section{Takeda 2009 \{published data only\}}

Takeda Y, Kawashima T, Kiyota K, Oda S, Morimoto N, Kobata $\mathrm{H}$, et al. Feasibility study of immediate pharyngeal cooling initiation in cardiac arrest patients after arrival at the emergency room. Resuscitation 2014;85(12):1647-53. [PUBMED: 25263513]

Takeda Y, Shiraishi K, Naito H, Hagioka S, Morimoto N, Morita K. A randomized controlled trial of pharyngeal cooling system during cardiopulmonary resuscitation. Journal of Neurosurgical Anesthesiology 2009;21(4):407-8. [DOI: http:// dx.doi.org/10.1097/01.ana.0000358102.35410.08; EMBASE: 70034508]

\section{Additional references}

\section{Absalom 1999}

Absalom AR, Bradley P, Soar J. Out-of-hospital cardiac arrests in an urban/rural area during 1991 and 1996: have emergency medical service changes improved outcome?. Resuscitation 1999;40:3-9. [MEDLINE: 10321842]

\section{Arrich 2006}

Arrich J, Sterz F, Fleischhackl R, Uray T, Losert H, Kliegel A, et al. Gender modifies the influence of age on outcome after successfully resuscitated cardiac arrest: a retrospective cohort study. Medicine 2006;85(5):288-94. [MEDLINE: 16974213]

\section{Baumann 2009}

Baumann E, Preston E, Slinn J, Stanimirovic D. Post-ischemic hypothermia attenuates loss of the vascular basement membrane proteins, agrin and SPARC, and the blood-brain barrier disruption after global cerebral ischemia. Brain Research 2009;1269:185-97. [PUBMED: 19285050]

\section{Bro-Jeppesen 2013}

Bro-Jeppesen J, Hassager C, Wanscher M, Soholm H, Thomsen JH, Lippert FK, et al. Post-hypothermia fever is associated with increased mortality after out-of-hospital cardiac arrest. Resuscitation 2013;84(12):1734-40. [PUBMED: 23917079] 


\section{Böttiger 1999}

Böttiger BW, Grabner C, Bauer H, Bode C, Weber T, Motsch J, et al. Long term outcome after out-of-hospital cardiac arrest with physician staffed emergency medical services: the Utstein style applied to a midsized urban/suburban area. Heart 1999;82:674-9. [MEDLINE: 10573491]

\section{Callaway 2015}

Callaway CW, Soar J, Aibiki M, Bottiger BW, Brooks SC, Deakin CD, et al. Part 4: Advanced Life Support: 2015 International Consensus on Cardiopulmonary Resuscitation and Emergency Cardiovascular Care Science With Treatment Recommendations. Circulation 2015;132(16 Suppl 1):S84-S145. [PUBMED: 26472860]

\section{Cheung 2006}

Cheung KW, Green RS, Magee KD. Systematic review of randomized controlled trials of therapeutic hypothermia as a neuroprotectant in post cardiac arrest patients. Canadian Journal of Emergency Medical Care 2006;8(5):329-37. [MEDLINE: 17338844]

\section{Chugh 2004}

Chugh SS, Jui J, Gunson K, Stecker EC, John BT, Thompson B, et al. Current burden of sudden cardiac death: multiple source surveillance versus retrospective death certificate-based review in a large U.S. community. Journal of the American College of Cardiology 2004;44(6):1268-75. [PUBMED: 15364331]

\section{D'Cruz 2002}

D'Cruz BJ, Fertig KC, Filiano AJ, Hicks SD, DeFranco DB, Callaway $\mathrm{CW}$. Hypothermic reperfusion after cardiac arrest augments brain-derived neurotrophic factor activation. Journal of Cerebral Blood Flow and Metabolism 2002;22(7):843-51. [PUBMED: 12142569]

\section{Deakin 2010}

Deakin CD, Nolan JP, Soar J, Sunde K, Koster RW, Smith GB, et al. European Resuscitation Council Guidelines for Resuscitation 2010 Section 4. Adult advanced life support. Resuscitation 2010;81(10):1305-52. [PUBMED: 20956049]

\section{Egger 1997}

Egger M, Davey Smith G, Schneider M, Minder C. Bias in meta-analysis detected by a simple, graphical test. $B M J$ 1997;315:629-34. [MEDLINE: 9310563]

\section{Finn 2001}

Finn JC, Jacobs IG, Holman CD, Oxer HF. Outcomes of out-ofhospital cardiac arrest patients in Perth, Western Australia, 1996-1999. Resuscitation 2001;51:247-55. [MEDLINE: 11738774]

\section{Fischer 1997}

Fischer M, Fischer NJ, Schuttler J. One-year survival after out-ofhospital cardiac arrest in Bonn city: outcome report according to the 'Utstein style'. Resuscitation 1997;33:233-43. [MEDLINE: 9044496]

\section{Fourth Framework Programme}

The Fourth Framework Programme. The European Commission [updated May 2001]. http://ec.europa.eu/research/fp4.html. (accessed [09/05/2015]).

\section{FWF}

Austrian Science Foundation (FWF). Available from www.fwf.ac.at/en/ (accessed April 2015).

\section{GAMBRO}

Gambro Hospal Austria GmbH. Available from www.gambro.at (accessed May 2015).

\section{Giraud 1996}

Giraud F, Rascle C, Guignand M. Out-of-hospital cardiac arrest. Evaluation of one year of activity in Saint-Etienne's emergency medical system using the Utstein style. Resuscitation 1996;33:19-27. [MEDLINE: 8959769]

\section{GRADEPRO [Computer program]}

McMaster University. GRADEpro. [Computer program on www.gradepro.org]. Version [6th of May 2015]. McMaster University, 2014.

\section{Guyatt 2011}

Guyatt GH, Oxman AD, Kunz R, Brozek J, Alonso-Coello P, Rind D, et al. GRADE guidelines 6 . Rating the quality of evidence--imprecision. Journal of clinical epidemiology 2011;64(12):1283-93. [PUBMED: 21839614]

\section{Hachimi-Idrissi 2004}

Hachimi-Idrissi S, Van Hemelrijck A, Michotte A, Smolders I, Sarre S, Ebinger G, et al. Postischemic mild hypothermia reduces neurotransmitter release and astroglial cell proliferation during reperfusion after asphyxial cardiac arrest in rats. Brain Research 2004;1019(1-2):217-25. [PUBMED: 15306256]

\section{Haukoos 2004}

Haukoos JS, Lewis RJ, Niemann JT. Prediction rules for estimating neurologic outcome following out-of-hospital cardiac arrest. Resuscitation 2004;63:145-55. [MEDLINE: 15531065]

\section{Herlitz 1999}

Herlitz J, Bahr J, Fischer M, Kuisma M, Lexow K, Thorgeirsson G. Resuscitation in Europe: a tale of five European regions. Resuscitation 1999;41:121-31. [MEDLINE: 10488934]

\section{Herlitz 2003a}

Herlitz J, Bang A, Gunnarsson J, Engdahl J, Karlson BW, Lindqvist J, et al. Factors associated with survival to hospital discharge among patients hospitalised alive after out of hospital cardiac arrest: change in outcome over 20 years in the community of Goteborg, Sweden. Heart 2003;89(1):25-30. [MEDLINE: 12482785]

\section{Herlitz 2003b}

Herlitz J, Engdahl J, Svensson L, Young M, Angquist KA, Holmberg S. Changes in demographic factors and mortality 
after out-of-hospital cardiac arrest in Sweden. Coronary Artery Disease 2005;16(1):51-7. [MEDLINE: 15654201]

\section{Higgins 2003}

Higgins JPT, Thompson SG, Deeks JJ, Altman DG. Measuring inconsistency in meta-analyses. BMJ 2003;327:557-60. [MEDLINE: 12958120]

\section{Higgins 2011}

Higgins JPT, Green S (editors). Cochrane Handbook for Systematic Reviews of Interventions Version 5.1.0 [updated March 2011]. The Cochrane Collaboration, 2011. www.cochranehandbook.org, 2011. [ISBN: 0727909045]

\section{Holzer 2005}

Holzer M, Bernard SA, Hachimi-Idrissi S, Roine RO, Sterz F, Müllner M, on behalf of the Collaborative Group on Induced Hypothermia for Neuroprotection After Cardiac Arrest. Hypothermia for neuroprotection after cardiac arrest: systematic review and individual patient data meta-analysis. Critical Care Medicine 2005;33(2):414-8. [MEDLINE: 15699847]

\section{Holzer 2010}

Holzer M. Targeted temperature management for comatose survivors of cardiac arrest. The New England Journal of Medicine 2010;363(13):1256-64. [PUBMED: 20860507]

\section{Jennings 2001}

Jennings P, Pasco J. Survival from out-of-hospital cardiac arrest in the Geelong region of Victoria, Australia. Emergency Medicine 2001;13:319-25. [MEDLINE: 11554863]

\section{Karibe 1994}

Karibe H, Zarow GJ, Graham SH, Weinstein PR. Mild intraischemic hypothermia reduces postischemic hyperperfusion, delayed postischemic hypoperfusion, bloodbrain barrier disruption, brain edema, and neuronal damage volume after temporary focal cerebral ischemia in rats. Journal of Cerebral Blood Flow and Metabolism 1994;14:620-7. [MEDLINE: 8014209]

\section{Kim 2001}

Kim C, Fahrenbruch CE, Cobb LA, Eisenberg MS. Out-ofhospital cardiac arrest in men and women. Circulation 2001;104:2699-703. [MEDLINE: 11723022]

\section{Kuisma 1996}

Kuisma M, Maatta T. Out-of-hospital cardiac arrests in Helsinki: Utstein style reporting. Heart 1996;76:18-23. [MEDLINE: 8774321]

\section{Langendam 2013}

Langendam MW, Akl EA, Dahm P, Glasziou P, Guyatt G, Schünemann HJ. Assessing and presenting summaries of evidence in Cochrane Reviews. Systematic Reviews 2013;2:81. [PUBMED: 24059250]

\section{Leary 2013}

Leary M, Grossestreuer AV, lannacone S, Gonzalez M, Shofer FS, Povey $\mathrm{C}$, et al. Pyrexia and neurologic outcomes after therapeutic hypothermia for cardiac arrest. Resuscitation 2013;84(8):1056-61. [PUBMED: 23153649]

\section{Lee 2010}

Lee HC, Chuang HC, Cho DY, Cheng KF, Lin PH, Chen CC. Applying cerebral hypothermia and brain oxygen monitoring in treating severe traumatic brain injury. World Neurosurgery 2010;74(6):654-60. [PUBMED: 21492636]

\section{Leung 2001}

Leung LP, Wong TW, Tong HK, Lo CB, Kan PG. Out-of-hospital cardiac arrest in Hong Kong. Prehospital Emergency Care 2001;5:308-11. [MEDLINE: 11446552]

\section{McCullough 1999}

McCullough JN, Zhang N, Reich DL, Juvonen TS, Klein JJ, Spielvogel D, et al. Cerebral metabolic suppression during hypothermic circulatory arrest in humans. The Annals of Thoracic Surgery 1999;67(6):1895-9; discussion 1919-21. [PUBMED: 10391334]

\section{McNally 2011}

McNally B, Robb R, Mehta M, Vellano K, Valderrama AL, Yoon PW, et al. Out-of-hospital cardiac arrest surveillance --- Cardiac Arrest Registry to Enhance Survival (CARES), United States, October 1, 2005--December 31, 2010. Morbidity and Mortality Weekly Report. Surveillance Summaries 2011;60(8):1-19. [PUBMED: 21796098]

\section{Mizuhara 1996}

Mizuhara A. [The protective effect of hypothermia in a new transient cerebral ischemic model of the rat--A 31P magnetic resonance spectroscopy in vivo study]. Nippon Kyobu Geka Gakkai Zasshi 1996;44:1-8. [MEDLINE: 8683162]

\section{Negovsky 1988}

Negovsky VA. Postresuscitation disease. Critical Care Medicine 1988;16:942-6. [MEDLINE: 3048895]

\section{Nielsen 2011}

Nielsen N, Friberg H, Gluud C, Herlitz J, Wetterslev J. Hypothermia after cardiac arrest should be further evaluated - a systematic review of randomised trials with meta-analysis and trial sequential analysis. International Journal of Cardiology 2011;151(3):333-41. [PUBMED: 20591514]

\section{Nolan 2003}

Nolan JP, Morley PT, Hoek TL, Hickey RW, Advancement Life Support Task Force of the International Liaison Committee on Resuscitation. Therapeutic hypothermia after cardiac arrest. An advisory statement by the Advancement Life Support Task Force of the International Liaison Committee on Resuscitation. Resuscitation 2003;57(3):231-5. [MEDLINE: 12858857]

\section{Okuda 1986}

Okuda C, Saito A, Miyazaki M, Kuriyama K. Alteration of the turnover of dopamine and 5-hydroxytryptamine in rat brain associated with hypothermia. Pharmacology, Biochemistry and Behaviour 1986;24:79-83. [MEDLINE: 2418447] 


\section{Peberdy 2010}

Peberdy MA, Callaway CW, Neumar RW, Geocadin RG, Zimmerman JL, Donnino M, et al. Part 9: post-cardiac arrest care: 2010 American Heart Association Guidelines for Cardiopulmonary Resuscitation and Emergency Cardiovascular Care. Circulation 2010;122 Suppl 3(18):768-86. [PUBMED: 20956225]

\section{Rea 2004}

Rea TD, Pearce RM, Raghunathan TE, Lemaitre RN, Sotoodehnia N, Jouven X, et al. Incidence of out-ofhospital cardiac arrest. The American Journal of Cardiology 2004;93(12):1455-60. [MEDLINE: 15194012]

\section{RevMan 5.3 [Computer program]}

The Nordic Cochrane Centre, The Cochrane Collaboration. Review Manager (RevMan). Version 5.3. Copenhagen: The Nordic Cochrane Centre, The Cochrane Collaboration, 2014.

\section{Rewers 2000}

Rewers M, Tilgreen RE, Crawford ME, Hjortso N. One-year survival after out-of-hospital cardiac arrest in Copenhagen according to the 'Utstein style'. Resuscitation 2000;47:137-46. [MEDLINE: 11008151]

\section{Rosomoff 1954}

Rosomoff H, Holaday D. Cerebral blood flow and cerebral oxygen consumption during hypothermia. American Journal of Physiology 1954;179:85-8. [MEDLINE: 13207391]

\section{Schreckinger 2009}

Schreckinger M, Marion DW. Contemporary management of traumatic intracranial hypertension: is there a role for therapeutic hypothermia?. Neurocritical Care 2009;11(3):427-36. [PUBMED: 19644773]

\section{Soar 2015}

Soar J, Callaway CW, Aibiki M, Bottiger BW, Brooks SC, Deakin CD, et al. Part 4: Advanced life support: 2015 International Consensus on Cardiopulmonary Resuscitation and Emergency Cardiovascular Care Science with Treatment Recommendations. Resuscitation 2015;95:e71-e120. [PUBMED: 26477429]

\section{Stiell 2009}

Stiell IG, Nesbitt LP, Nichol G, Maloney J, Dreyer J, Beaudoin T, et al. Comparison of the Cerebral Performance Category score and the Health Utilities Index for survivors of cardiac arrest. Annals of Emergency Medicine 2009;53(2):241-8. [PUBMED: 18450329]

\section{Storm 2014}

Storm C. The use of hypothermia and outcome post cardiopulmonary resuscitation in 2014. Revista Brasileira de Terapia Intensiva 2014;26(2):83-5. [PUBMED: 25028942]

\section{Stub 2014}

Stub D. Targeted temperature management after cardiac arrest. The New England Journal of Medicine 2014; Vol. 370, issue 14:1358. [PUBMED: 24693905]

\section{Sun 2010}

Sun S, Tang W, Song F, Yu T, Ristagno G, Shan Y, et al. The effects of epinephrine on outcomes of normothermic and therapeutic hypothermic cardiopulmonary resuscitation. Critical Care Medicine 2010;38(11):2175-80. [PUBMED: 20693888]

\section{Szelenyi 2012}

Szelenyi M, Laszlo Z, Szabo Z, Kromplak Z, Tischler E, Lakatos M, et al. Hypothermia down-regulates the LPS-induced norepinephrine (NE) release in ischaemic human heart cells. Brain Research Bulletin 2012;87(1):67-73. [PUBMED: 21963948]

\section{Takasu 1996}

Takasu A, Yagi K, Okada Y. Effect of mild hypothermia on ischemia-induced release of endothelin-1 in dog brain. Resuscitation 1996;31:59-64. [MEDLINE: 8701110]

\section{Testori 2012}

Testori C, Sterz F, Holzer M, Losert H, Arrich J, Herkner H, et al. The beneficial effect of mild therapeutic hypothermia depends on the time of complete circulatory standstill in patients with cardiac arrest. Resuscitation 2012;83(5):596-601. [PUBMED: 22138057]

\section{Thompson 2001}

Thompson SG. Why sources of heterogeneity in meta-analysis should be investigated. In: Chalmers I, Altman DG editor(s). Systematic Reviews. 1st Edition. London: BMJ Publishing Group, 1995:48-63.

\section{Tiainen 2003}

Tiainen M, Roine RO, Pettila V, Takkunen O. Serum neuronspecific enolase and S-100B protein in cardiac arrest patients treated with hypothermia. Stroke 2003;34(12):2881-6. [PUBMED: 14631087]

\section{Tiainen 2005}

Tiainen M, Kovala TT, Takkunen OS, Roine RO. Somatosensory and brainstem auditory evoked potentials in cardiac arrest patients treated with hypothermia. Critical Care Medicine 2005;33(8):1736-40. [PUBMED: 16096450]

\section{Tiainen 2007}

Tiainen M, Poutiainen E, Kovala T, Takkunen O, Happola O, Roine RO. Cognitive and neurophysiological outcome of cardiac arrest survivors treated with therapeutic hypothermia. Stroke 2007;38(8):2303-8. [PUBMED: 17585081]

\section{Weston 1997}

Weston CF, Jones SD, Wilson RJ. Outcome of out-of-hospital cardiorespiratory arrest in south Glamorgan. Resuscitation 1997;34:227-33. [MEDLINE: 9178383]

\section{Xiao 2013}

Xiao G, Guo Q, Shu M, Xie X, Deng J, Zhu Y, et al. Safety profile and outcome of mild therapeutic hypothermia in patients following cardiac arrest: systematic review and meta-analysis. Emergency Medicine Journal 2013;30(2):91-100. [PUBMED: 22660549] 


\section{Zeiner 2001}

Zeiner A, Holzer M, Sterz F, Schorkhuber W, Eisenburger P, Havel $C$, et al. Hyperthermia after cardiac arrest is associated with an unfavorable neurologic outcome. Archives of Internal Medicine 2001;161(16):2007-12. [MEDLINE: 11525703]

\section{References to other published versions of this review}

\section{Arrich 2003}

Arrich J, Herkner H, Holzer M, Müllner M. Hypothermia for neuroprotection after cardiopulmonary resuscitation. Cochrane Database of Systematic Reviews 2003, Issue 2. [DOI: 10.1002/14651858.CD004128]

\section{CHARACTERISTICS OF STUDIES}

Characteristics of included studies [ordered by study ID]

\section{Arrich 2009}

Arrich J, Holzer M, Herkner H, Müllner M. Hypothermia for neuroprotection in adults after cardiopulmonary resuscitation. Cochrane Database of Systematic Reviews 2009, Issue 4. [DOI: 10.1002/14651858.CD004128.pub2]

\section{Arrich 2012}

Arrich J, Holzer M, Havel C, Mullner M, Herkner H. Hypothermia for neuroprotection in adults after cardiopulmonary resuscitation. The Cochrane Database of Systematic Reviews 2012;9:CD004128. [PUBMED: 22972067]

* Indicates the major publication for the study

Bernard 2002

\begin{tabular}{ll}
\hline Methods & Randomization: pre-hospital \\
\hline Participants & Total number of participants 77, mean age 66 years, 33\% female \\
Out-of-hospital cardiac arrest of cardiac cause, ventricular fibrillation as first cardiac rhythm, comatose \\
after resuscitation \\
Participating sites: Australian university and community hospitals \\
Multi-centre: yes \\
Language: English \\
Allocation concealment: not applicable (odd and even days) \\
Outcome assessor blind: yes \\
Intention-to-treat analysis: yes \\
Groups comparable: more females and more bystander CPR in hypothermia group \\
Follow-up > $80 \%$ of randomly assigned participants: yes
\end{tabular}

Means of cooling: ice packs placed around head, neck, torso and limbs

Cooling rate: time from ROSC to target temperature: 2 hours

Target temperature: $33^{\circ} \mathrm{C}$

Duration of cooling: 12 hours after target temperature was reached

Rewarming: passive after 12 hours, active after 18 hours

Outcomes

$$
\begin{aligned}
& \text { Survival with good neurological function to be sent home or to a rehabilitation facility at discharge } \\
& \text { In-hospital death } \\
& \text { Haemodynamic, biochemical and haematological effects of hypothermia } \\
& \text { For IPD analysis, best ever reached CPC during hospital stay and CPC discharge provided }
\end{aligned}
$$


Bernard 2002 (Continued)

Notes Randomization: odd and even days

\section{Risk of bias}

\begin{tabular}{lll}
\hline Bias & Authors' judgement & Support for judgement \\
\hline $\begin{array}{l}\text { Random sequence genera- } \\
\text { tion (selection bias) }\end{array}$ & High risk & Odd and even days \\
\hline $\begin{array}{l}\text { Allocation concealment } \\
\text { (selection bias) }\end{array}$ & High risk & Odd and even days \\
\hline $\begin{array}{l}\text { Blinding of participants } \\
\text { and personnel (perfor- } \\
\text { mance bias) }\end{array}$ & Low risk & Treating personnel not blinded \\
All outcomes & \\
\hline $\begin{array}{l}\text { Incomplete outcome data } \\
\text { (attrition bias) }\end{array}$ & Low risk & Complete follow-up \\
All outcomes & & \\
\hline $\begin{array}{l}\text { Other bias } \\
\text { Funding }\end{array}$ & Low risk & No other major biases seen \\
\hline $\begin{array}{l}\text { Blinding of outcome as- } \\
\text { sessment (detection bias) } \\
\begin{array}{l}\text { All oudcomes neurologic outcome } \\
\hline\end{array}\end{array}$ & Low risk & No information provided \\
\hline
\end{tabular}

Blinding of outcome as- Low risk Outcome assessment blinded

sessment (detection bias)

Survivial

Survival

\section{HACA 2002}

\begin{tabular}{ll}
\hline Methods & Randomization: in hospital \\
\hline Participants & Total number of participants 275 , mean age 59 years, $24 \%$ female \\
In-hospital and out-of-hospital bystander-witnessed cardiac arrest of presumed cardiac cause, ventric- \\
ular fibrillation or non-perfusing ventricular tachycardia as first cardiac rhythm, comatose after resusci- \\
tation \\
Participating sites: European university and community hospitals \\
Multi-centre: yes \\
Language: English \\
Allocation concealment: opaque envelopes \\
Outcome assessor blind: yes \\
Intention-to-treat analysis: yes
\end{tabular}


HACA 2002 (Continued)

Groups comparable: significantly more diabetes and coronary heart disease and bystander CPR in control group

Follow-up $>80 \%$ of randomly assigned participants: yes

Interventions

Therapeutic hypothermia vs standard intensive care treatment

Means of cooling: cooling blanket that covered the whole body and released cooled air

Cooling rate: time from ROSC to target temperature: median of 8 hours

Target temperature: $32^{\circ} \mathrm{C}$ to $34^{\circ} \mathrm{C}$

Duration of cooling: median 24 hours

Rewarming: passive over 8 hours

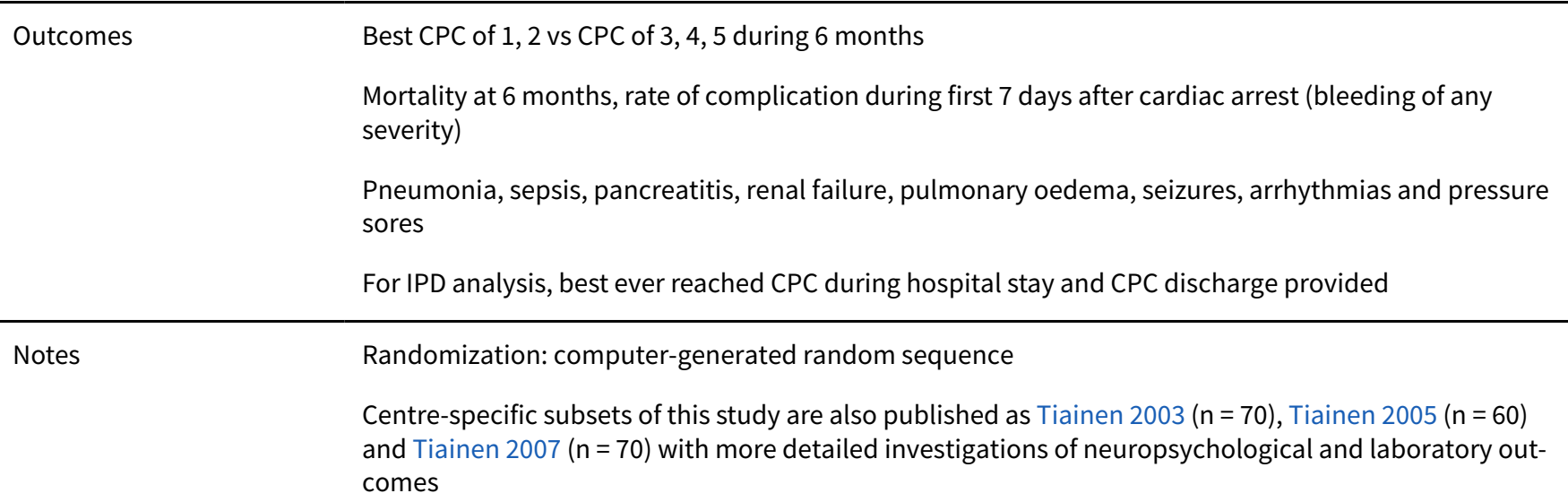

\section{Risk of bias}

Bias Authors' judgement Support for judgement

Random sequence genera- Low risk Treatment assignments randomly generated by computer in blocks of 10 , with tion (selection bias) stratification according to centre

\begin{tabular}{ll}
\hline $\begin{array}{l}\text { Allocation concealment } \\
\text { (selection bias) }\end{array}$ & Low risk
\end{tabular}

\begin{tabular}{ll}
\hline $\begin{array}{l}\text { Blinding of participants } \\
\text { and personnel (perfor- }\end{array}$ & Low risk
\end{tabular}
mance bias)

All outcomes

\begin{tabular}{lll}
\hline $\begin{array}{l}\text { Incomplete outcome data } \\
\text { (attrition bias) } \\
\text { All outcomes }\end{array}$ & Low risk & Two participants lost to follow-up, properly addressed \\
\hline Other bias & Low risk & No other major biases seen \\
\hline Funding & Low risk & $\begin{array}{l}\text { Supported by grants of the Fourth RTD Framework Programme 1994-1998 of } \\
\text { the European Union, the Austrian Ministry of Science and Transport and the } \\
\text { Austrian Science Foundation }\end{array}$ \\
\hline $\begin{array}{l}\text { Blinding of outcome as- } \\
\text { sessment (detection bias) } \\
\text { Good neurologic outcome }\end{array}$ & Low risk & $\begin{array}{l}\text { Personnel involved in care of patients during first 48 hours after cardiac arrest } \\
\text { could not be blinded to treatment assignments. However, physicians respon- }\end{array}$ \\
\hline
\end{tabular}


HACA 2002 (Continued)

All outcomes sible for assessing neurological outcome within first 6 months after the arrest unaware of treatment assignments
Blinding of outcome as- Low risk sessment (detection bias)

Survivial

Survival
Assessors of survival within first 6 months after arrest were unaware of treatment assignments

Hachimi-Idrissi 2001

\begin{tabular}{ll}
\hline Methods & Randomization: in-hospital \\
\hline Participants & Total number of participants 33, mean age 72 years, 39\% female \\
Out-of-hospital cardiac arrest of cardiac cause, pulseless electrical activity or asystole as first cardiac \\
rhythm, comatose after resuscitation \\
Participating site: Belgian university hospital \\
Multi-centre: no \\
Language: English \\
Outcome assessor blind: yes \\
Intention-to-treat analysis: yes \\
Groups comparable: yes, although groups were small, no significant differences \\
Follow-up > 80\% of randomly assigned participants: yes \\
\hline
\end{tabular}

Interventions

Therapeutic hypothermia vs standard post-resuscitation care protocol

Means of cooling: helmet device placed around head and neck and containing a solution of aqueous glycerol

Cooling rate: starting point until target temperature not clearly stated

Target temperature: $34^{\circ} \mathrm{C}$

Duration of cooling: start of cooling to start of rewarming, 4 hours

Rewarming: passive over 8 hours

Outcomes

Haemodynamic data, arterial $\mathrm{pH}$, electrolytes, haematological data

Complications such as pneumonia, sepsis, cardiac arrhythmia, coagulopathy

Survival to hospital discharge and overall performance categories (OPCs)

For IPD analysis, best ever reached CPC during hospital stay and CPC discharge provided

Notes

Randomization: random number tables

IPD included 33 participants; article reported on only 30, as follow-up was not completed at the time of submission

\section{Risk of bias}

\section{Bias \\ Authors' judgement Support for judgement}


Hachimi-Idrissi 2001 (Continued)
Random sequence genera- Low risk
Random sequence generated with random number tables tion (selection bias)

\begin{tabular}{|c|c|c|}
\hline $\begin{array}{l}\text { Allocation concealment } \\
\text { (selection bias) }\end{array}$ & Low risk & $\begin{array}{l}\text { After stabilization and insertion of catheters, participants prospectively blind } \\
\text { ly randomly assigned to } 2 \text { groups (treatment allocation concealed by use of } \\
\text { opaque envelopes) }\end{array}$ \\
\hline
\end{tabular}

Blinding of participants $\quad$ Low risk
and personnel (perfor-
mance bias)

\begin{tabular}{|c|c|c|}
\hline $\begin{array}{l}\text { Incomplete outcome data } \\
\text { (attrition bias) } \\
\text { All outcomes }\end{array}$ & Low risk & Differences between published report and IPD properly reported \\
\hline Other bias & Low risk & No other major biases seen \\
\hline Funding & Unclear risk & No information provided \\
\hline $\begin{array}{l}\text { Blinding of outcome as- } \\
\text { sessment (detection bias) } \\
\text { Good neurologic outcome } \\
\text { All outcomes }\end{array}$ & Low risk & Outcome assessors blind to the intervention \\
\hline $\begin{array}{l}\text { Blinding of outcome as- } \\
\text { sessment (detection bias) } \\
\text { Survivial } \\
\text { Survival }\end{array}$ & Low risk & Outcome assessors blind to the intervention \\
\hline
\end{tabular}

\section{Laurent 2005}

\begin{tabular}{ll}
\hline Methods & Randomization: pre-hospital \\
\hline Participants & Total number of participants 42, mean age 52 years in HF group, 56 years in HF+HT group, 19\% female \\
& Out-of-hospital cardiac arrest of presumed cardiac cause, ventricular fibrillation or asystole as first car- \\
diac rhythm, comatose after resuscitation & Participating sites: French university and community hospital \\
& Multi-centre: yes \\
& Language: English \\
& Allocation concealment: opaque envelopes \\
& Outcome assessor blind: not stated \\
Intention-to-treat analysis: yes & Groups comparable: yes \\
Follow-up > 80\% of randomly assigned participants: yes
\end{tabular}


Laurent 2005 (Continued)

Cooling rate: 4 hours after ICU admission, median temperature $31.7^{\circ} \mathrm{C}$

Target temperature: $32^{\circ} \mathrm{C}$ to $33^{\circ} \mathrm{C}$

Duration of cooling: 24 hours

Rewarming: passive

\begin{tabular}{ll}
\hline Outcomes & Survival at 6 months \\
& $\begin{array}{l}\text { Rate of death by intractable shock in participants who had a favourable Glasgow Coma Scale (M5 or } \\
\text { M6) or who required sedation } \\
\text { Survival at CPC } 1,2 \text { vs all else at } 6 \text { months }\end{array}$ \\
\hline Notes & Randomization pre-hospital to save time for haemofiltration \\
& $\begin{array}{l}\text { We did not pool data from this study with data from the other } 3 \text { studies, as treatment schemes with } \\
\text { haemofiltration are not comparable with treatment schemes with non-haemofiltration treatment (clin- } \\
\text { ical heterogeneity) }\end{array}$
\end{tabular}

\section{Risk of bias}

\begin{tabular}{lll}
\hline Bias & Authors' judgement & Support for judgement \\
\hline $\begin{array}{l}\text { Random sequence genera- } \\
\text { tion (selection bias) }\end{array}$ & Low risk & Computer-generated 1/1/1 randomization sequence prepared for each centre \\
\hline $\begin{array}{l}\text { Allocation concealment } \\
\text { (selection bias) }\end{array}$ & Low risk & $\begin{array}{l}\text { Participants randomly allocated to treatment by use of sealed opaque en- } \\
\text { velopes }\end{array}$ \\
\hline $\begin{array}{l}\text { Blinding of participants } \\
\text { and personnel (perfor- } \\
\text { mance bias) }\end{array}$ & Low risk & Blinding to assigned treatment not feasible \\
All outcomes & & \\
\hline
\end{tabular}

\begin{tabular}{l}
\hline $\begin{array}{l}\text { Incomplete outcome data } \quad \text { Low risk } \\
\text { (attrition bias) }\end{array}$ \\
All outcomes
\end{tabular}

\begin{tabular}{|c|c|c|}
\hline Other bias & Low risk & No other major biases seen \\
\hline Funding & Unclear risk & $\begin{array}{l}\text { For this study, haemofiltration circuits, catheters and replacement fluid con- } \\
\text { centrates provided by GAMBRO AB, with estimated cost of } € 120 \text { per participant } \\
\text { treated by haemofiltration }\end{array}$ \\
\hline $\begin{array}{l}\text { Blinding of outcome as- } \\
\text { sessment (detection bias) } \\
\text { Good neurologic outcome } \\
\text { All outcomes }\end{array}$ & Unclear risk & Outcome assessor blind: not stated \\
\hline $\begin{array}{l}\text { Blinding of outcome as- } \\
\text { sessment (detection bias) } \\
\text { Survivial } \\
\text { Survival }\end{array}$ & Low risk & $\begin{array}{l}\text { Outcome assessor blind: not stated, but for survival, risk of bias regarded as } \\
\text { low }\end{array}$ \\
\hline
\end{tabular}


Mori 2000

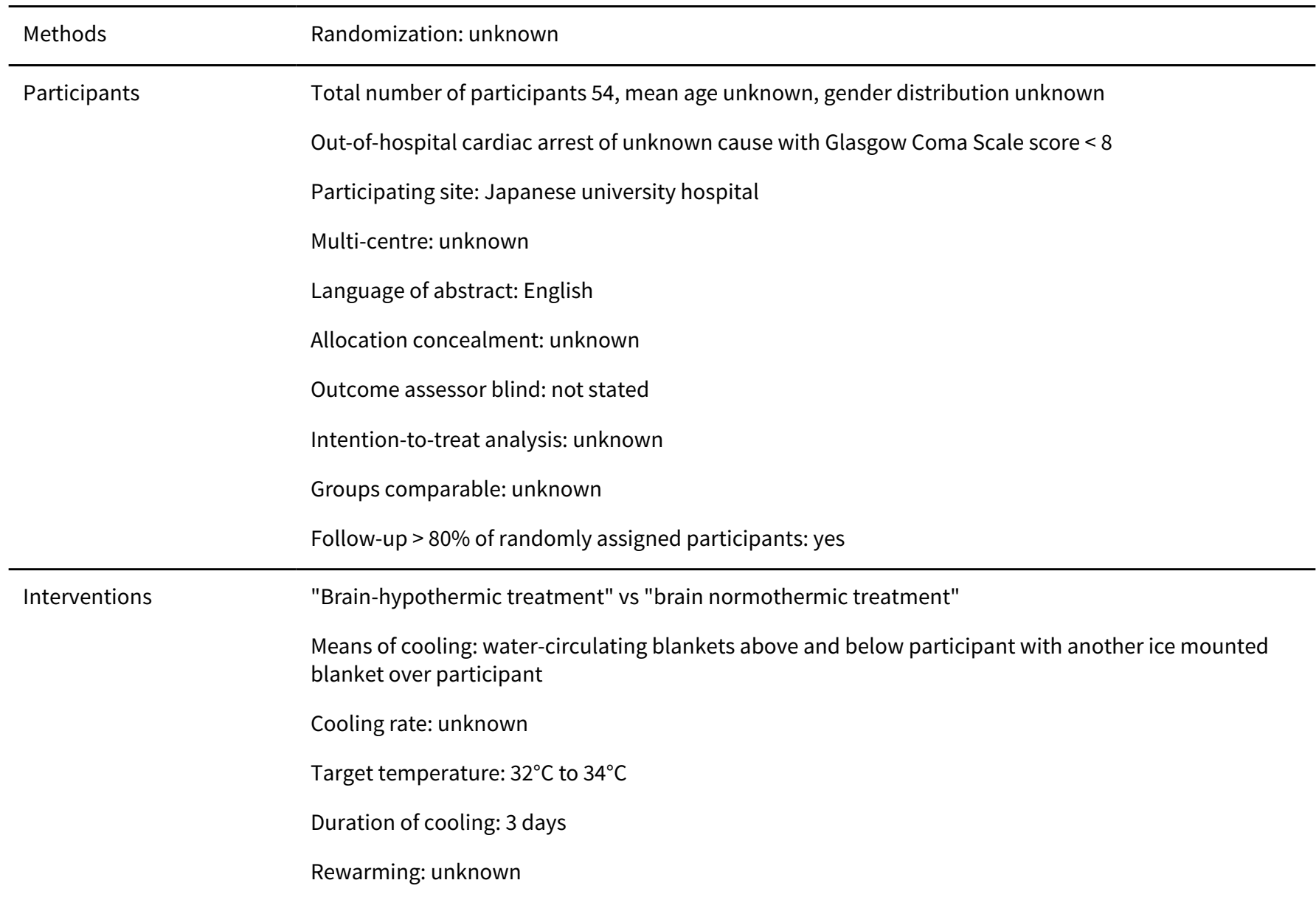

Outcomes Glasgow outcome scale at 1 month (5-point scale). Categories "moderate, mild, or no disabilities" de-
fined as "good neurological outcome"

Notes Only abstract published

Study now included in the pooled analysis, as we received information on the cooling method, whether cooling was applied locally or systemically

\section{Risk of bias}

\begin{tabular}{|c|c|c|}
\hline Bias & Authors' judgement & Support for judgement \\
\hline $\begin{array}{l}\text { Random sequence genera- } \\
\text { tion (selection bias) }\end{array}$ & Unclear risk & No information available from abstract and correspondence \\
\hline $\begin{array}{l}\text { Allocation concealment } \\
\text { (selection bias) }\end{array}$ & Unclear risk & No information available from abstract and correspondence \\
\hline $\begin{array}{l}\text { Blinding of participants } \\
\text { and personnel (perfor- } \\
\text { mance bias) } \\
\text { All outcomes }\end{array}$ & Unclear risk & No information available from abstract and correspondence \\
\hline $\begin{array}{l}\text { Incomplete outcome data } \\
\text { (attrition bias) } \\
\text { All outcomes }\end{array}$ & Unclear risk & No information available from abstract and correspondence \\
\hline
\end{tabular}


Mori 2000 (Continued)

\begin{tabular}{lll} 
Other bias & Unclear risk & No information available from abstract and correspondence \\
\hline Funding & Unclear risk & No information provided \\
\hline $\begin{array}{l}\text { Blinding of outcome as- } \\
\text { sessment (detection bias) } \\
\text { Good neurologic outcome }\end{array}$ & Unclear risk & No information available from abstract and correspondence \\
All outcomes & \\
\hline
\end{tabular}

Nielsen 2013

$\begin{array}{ll}\text { Methods } & \text { Randomization: } \\ \text { performed centrally with the use of a computer-generated assignment sequence }\end{array}$

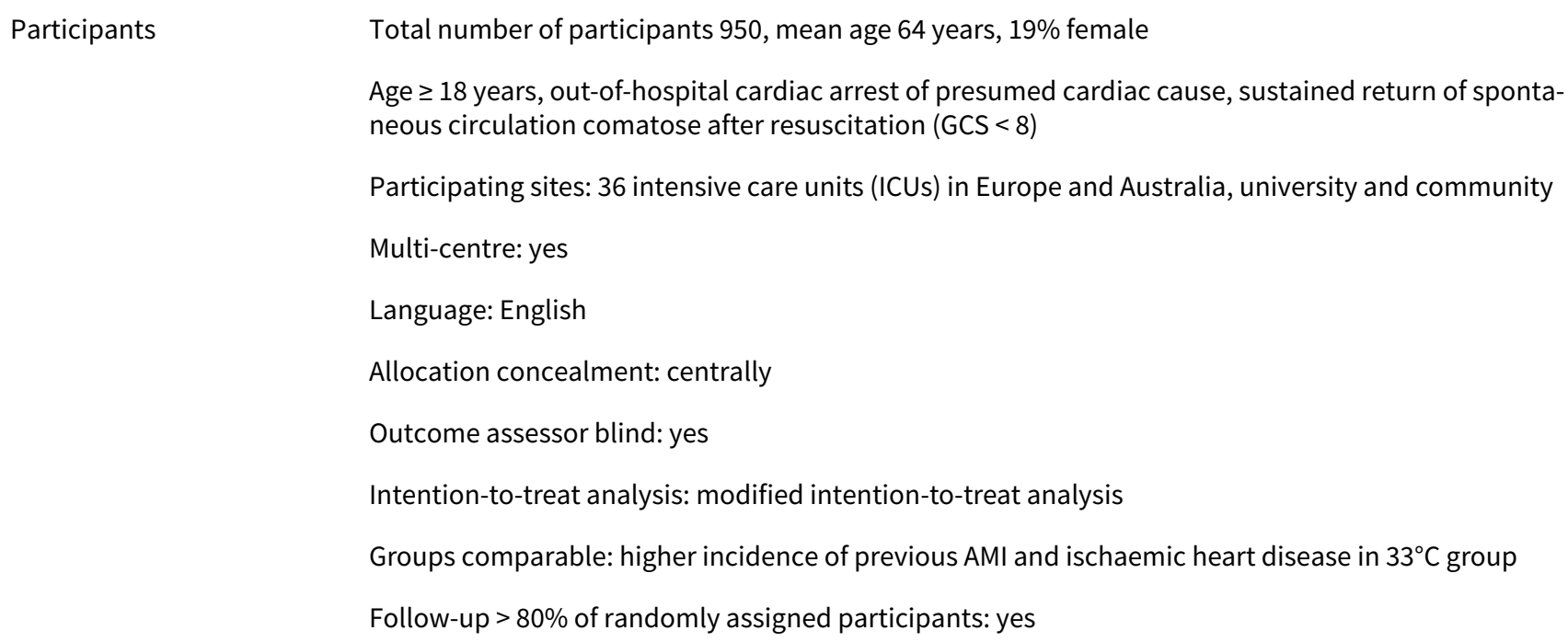

Outcomes All-cause mortality through the end of the trial

CPC of 3 to 5 around 180 days

Modified Rankin scale around 180 days

Mortality at 180 days

Individual neurological scores

Notes Control group differs $\left(36^{\circ}\right)$ from control group of other studies (no cooling)

\section{Risk of bias}

Bias Authors' judgement Support for judgement


Nielsen 2013 (Continued) $\begin{array}{ll}\begin{array}{l}\text { Random sequence genera- } \\ \text { tion (selection bias) }\end{array} & \begin{array}{l}\text { Randomization performed centrally with the use of a computer-generated as- } \\ \text { signment sequence }\end{array}\end{array}$

\begin{tabular}{ll}
\hline $\begin{array}{l}\text { Allocation concealment } \\
\text { (selection bias) }\end{array}$ & Low risk
\end{tabular}

\begin{tabular}{ll}
\hline Blinding of participants & Low risk \\
and personnel (perfor- & \\
mance bias) & \\
All outcomes & \\
\hline
\end{tabular}

Incomplete outcome data Low risk 11 out of 950 participants excluded after randomization (for various reasons)
(attrition bias)

All outcomes

\begin{tabular}{|c|c|c|}
\hline Other bias & Unclear risk & $\begin{array}{l}\text { Time from collapse to resuscitation } 1 \text { minute - considerably shorter than in } \\
\text { other trials } \\
\text { Period between return of spontaneous circulation and start of therapy not de- } \\
\text { fined, slow cooling rate } \\
\text { Dose-finding study with pragmatic study design - risk of non-effect in both } \\
\text { groups and misleading interpretation of equivalence }\end{array}$ \\
\hline Funding & Low risk & Funded by the Swedish Heart-Lung Foundation and others \\
\hline $\begin{array}{l}\text { Blinding of outcome as- } \\
\text { sessment (detection bias) } \\
\text { Good neurologic outcome } \\
\text { All outcomes }\end{array}$ & Low risk & Outcome assessment blinded \\
\hline $\begin{array}{l}\text { Blinding of outcome as- } \\
\text { sessment (detection bias) } \\
\text { Survivial } \\
\text { Survival }\end{array}$ & Low risk & Outcome assessment blinded \\
\hline
\end{tabular}

$\mathrm{AMI}=$ acute myocardial infarction

$\mathrm{CPC}=$ cerebral performance category

$\mathrm{CPR}=$ cardiopulmonary resuscitation

GCS = Glasgow Coma Scale

$\mathrm{HF}=$ haemofiltration

$\mathrm{HT}=$ hypothermia

$\mathrm{ICU}=$ intensive care unit

IPD = individual patient data

M5 = localizes painful stimuli

M6 = obeys commands

$\mathrm{OPC}=$ overall performance category

$\mathrm{ROSC}=$ restoration of spontaneous circulation

Characteristics of excluded studies [ordered by study ID]

\begin{tabular}{ll}
\hline Study & Reason for exclusion \\
\hline CAEP/ACMU 2013 & Substudy to Nielsen 2013; no outcome information on additional patients available \\
\hline Lopez-de-Sa 2012 & Intervention and control groups did not meet inclusion criteria; control group of $34^{\circ} \mathrm{C}$ and lower \\
\hline
\end{tabular}




\begin{tabular}{ll}
\hline Study & Reason for exclusion \\
\hline Takeda 2009 & $\begin{array}{l}\text { Intervention and control groups did not meet inclusion criteria, relevant numbers of participants in } \\
\text { control and intervention groups not continuously cooled }\end{array}$ \\
\hline
\end{tabular}

DATA AND ANALYSES

Comparison 1. Neurological outcome: therapeutic hypothermia versus no hypothermia

\begin{tabular}{|c|c|c|c|c|}
\hline Outcome or subgroup title & $\begin{array}{l}\text { No. of } \\
\text { studies }\end{array}$ & $\begin{array}{l}\text { No. of } \\
\text { partici- } \\
\text { pants }\end{array}$ & Statistical method & Effect size \\
\hline 1 All studies with subgroups & 6 & & Risk Ratio (M-H, Random, 95\% Cl) & Subtotals only \\
\hline $\begin{array}{l}1.1 \text { Conventional cooling vs no cool- } \\
\text { ing }\end{array}$ & 4 & 437 & Risk Ratio (M-H, Random, 95\% Cl) & $1.94[1.18,3.21]$ \\
\hline $\begin{array}{l}1.2 \text { Conventional cooling vs } 36^{\circ} \text { tem- } \\
\text { perature management }\end{array}$ & 1 & 933 & Risk Ratio (M-H, Random, 95\% Cl) & $0.97[0.85,1.11]$ \\
\hline $\begin{array}{l}1.3 \text { Cooling with haemofiltration vs } \\
\text { no cooling }\end{array}$ & 1 & 42 & Risk Ratio (M-H, Random, 95\% Cl) & $0.71[0.32,1.54]$ \\
\hline 2 Conventional cooling & 5 & 1370 & Risk Ratio (M-H, Random, 95\% Cl) & $1.53[1.02,2.29]$ \\
\hline $\begin{array}{l}2.1 \text { Conventional cooling vs no cool- } \\
\text { ing }\end{array}$ & 4 & 437 & Risk Ratio (M-H, Random, 95\% Cl) & $1.94[1.18,3.21]$ \\
\hline $\begin{array}{l}2.2 \text { Conventional cooling vs } 36^{\circ} \text { tem- } \\
\text { perature management }\end{array}$ & 1 & 933 & Risk Ratio (M-H, Random, 95\% Cl) & $0.97[0.85,1.11]$ \\
\hline
\end{tabular}

Analysis 1.1. Comparison 1 Neurological outcome: therapeutic hypothermia versus no hypothermia, Outcome 1 All studies with subgroups.

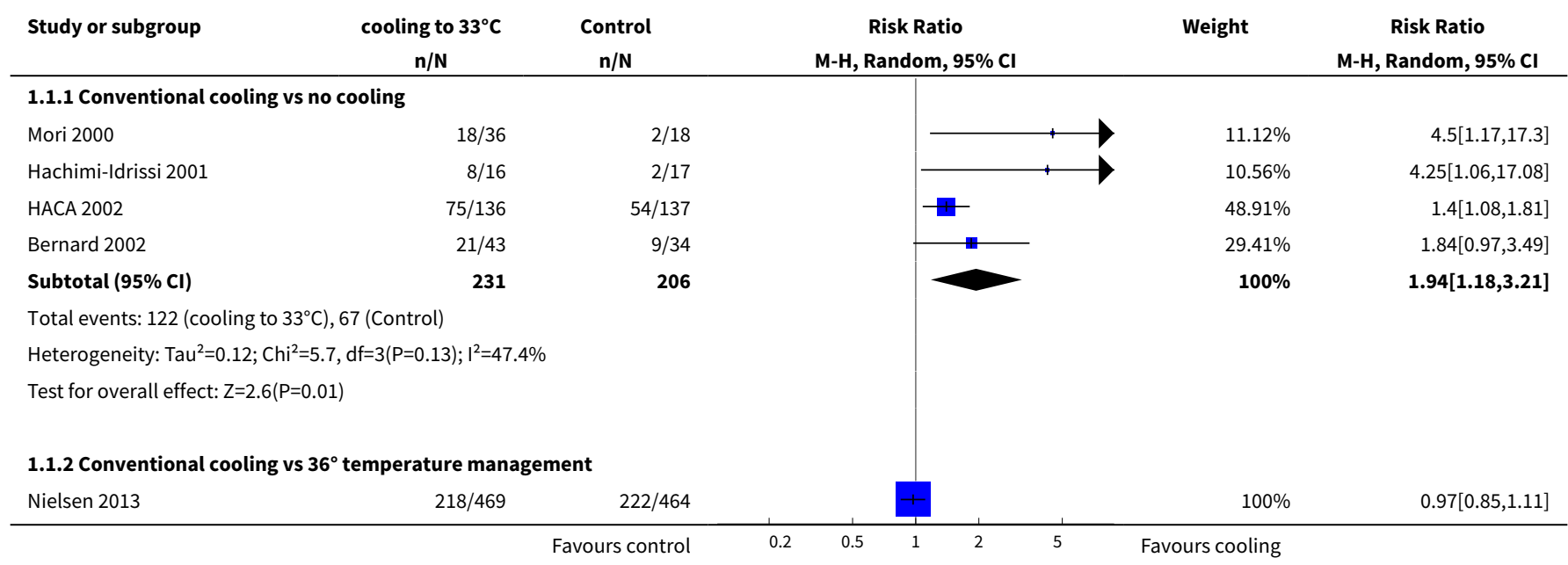




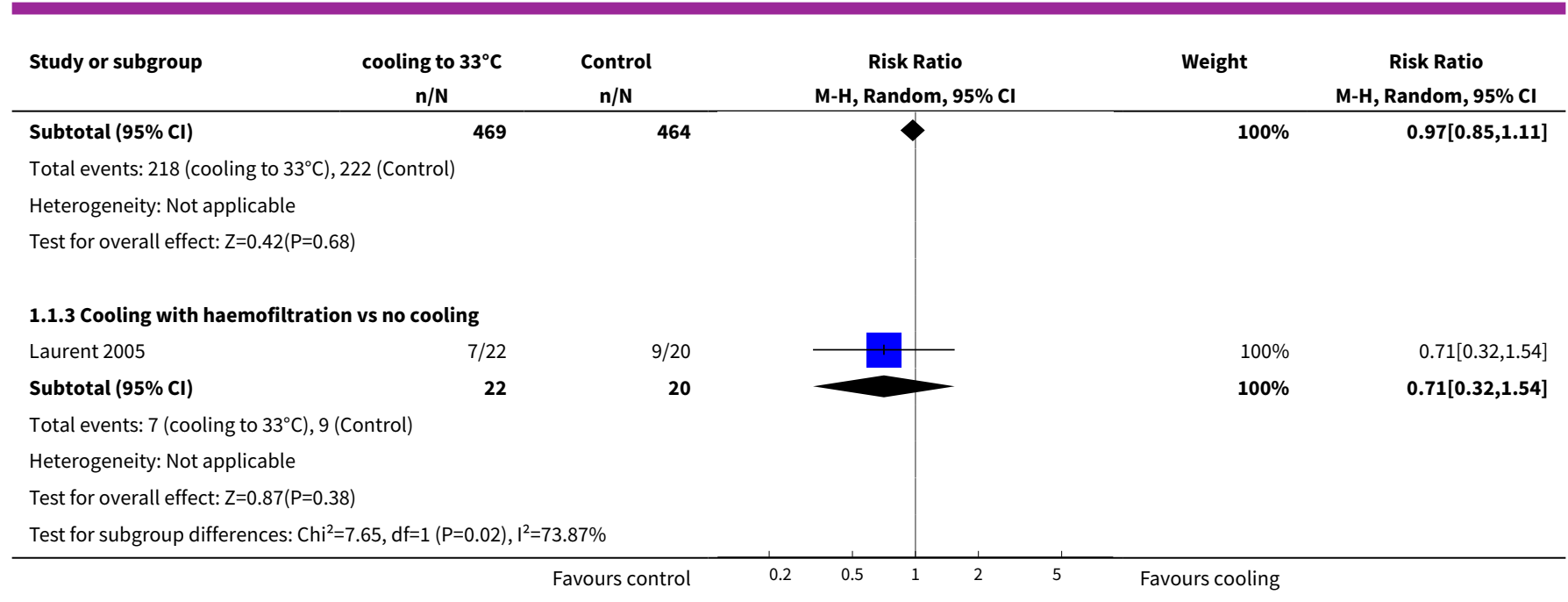

Analysis 1.2. Comparison 1 Neurological outcome: therapeutic hypothermia versus no hypothermia, Outcome 2 Conventional cooling.

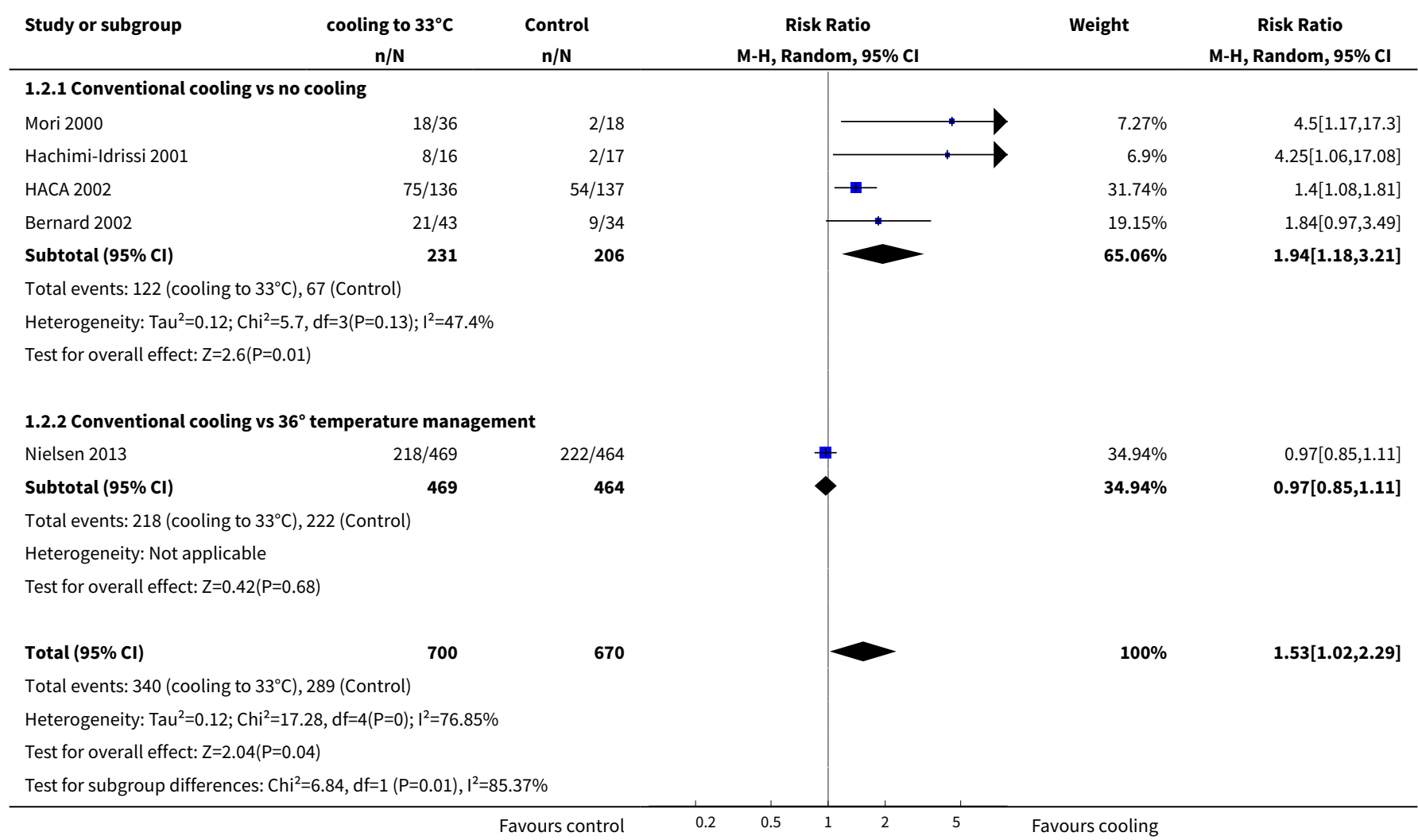


Comparison 2. Survival: therapeutic hypothermia versus no hypothermia

\begin{tabular}{|c|c|c|c|c|}
\hline Outcome or subgroup title & $\begin{array}{l}\text { No. of } \\
\text { studies }\end{array}$ & $\begin{array}{l}\text { No. of } \\
\text { partici- } \\
\text { pants }\end{array}$ & Statistical method & Effect size \\
\hline 1 All studies with subgroups & 5 & & Risk Ratio (M-H, Fixed, 95\% Cl) & Subtotals only \\
\hline $\begin{array}{l}1.1 \text { Conventional cooling vs no cool- } \\
\text { ing }\end{array}$ & 3 & 383 & Risk Ratio (M-H, Fixed, 95\% Cl) & $1.35[1.10,1.65]$ \\
\hline $\begin{array}{l}1.2 \text { Conventional cooling vs } 36^{\circ} \text { tem- } \\
\text { perature management }\end{array}$ & 1 & 939 & Risk Ratio (M-H, Fixed, 95\% Cl) & $0.97[0.86,1.10]$ \\
\hline $\begin{array}{l}1.3 \text { Cooling with haemofiltration vs } \\
\text { no cooling }\end{array}$ & 1 & 42 & Risk Ratio (M-H, Fixed, 95\% Cl) & $0.71[0.32,1.54]$ \\
\hline 2 Conventional cooling & 4 & 1322 & Risk Ratio (M-H, Fixed, 95\% Cl) & $1.07[0.96,1.19]$ \\
\hline $\begin{array}{l}2.1 \text { Conventional cooling vs no cool- } \\
\text { ing }\end{array}$ & 3 & 383 & Risk Ratio (M-H, Fixed, 95\% Cl) & $1.35[1.10,1.65]$ \\
\hline $\begin{array}{l}2.2 \text { Conventional cooling vs } 36^{\circ} \text { tem- } \\
\text { perature management }\end{array}$ & 1 & 939 & Risk Ratio (M-H, Fixed, 95\% Cl) & $0.97[0.86,1.10]$ \\
\hline
\end{tabular}

\section{Analysis 2.1. Comparison 2 Survival: therapeutic hypothermia} versus no hypothermia, Outcome 1 All studies with subgroups.

\begin{tabular}{|c|c|c|c|c|c|}
\hline Study or subgroup & $\begin{array}{c}\text { cooling to } 33^{\circ} \mathrm{C} \\
n / N\end{array}$ & $\begin{array}{c}\text { Control } \\
n / N\end{array}$ & $\begin{array}{c}\text { Risk Ratio } \\
\text { M-H, Fixed, 95\% Cl }\end{array}$ & Weight & $\begin{array}{c}\text { Risk Ratio } \\
\text { M-H, Fixed, 95\% Cl }\end{array}$ \\
\hline \multicolumn{6}{|c|}{ 2.1.1 Conventional cooling vs no cooling } \\
\hline Hachimi-Idrissi 2001 & $4 / 16$ & $1 / 17$ & & $1.21 \%$ & $4.25[0.53,34.1]$ \\
\hline HACA 2002 & $85 / 136$ & $67 / 137$ & & $83.43 \%$ & $1.28[1.03,1.58]$ \\
\hline Bernard 2002 & $21 / 43$ & $11 / 34$ & & $15.36 \%$ & $1.51[0.85,2.68]$ \\
\hline Subtotal $(95 \% \mathrm{Cl})$ & 195 & 188 & & $100 \%$ & $1.35[1.1,1.65]$ \\
\hline \multicolumn{6}{|c|}{ Total events: 110 (cooling to $33^{\circ} \mathrm{C}$ ), 79 (Control) } \\
\hline \multicolumn{6}{|c|}{ Heterogeneity: $\operatorname{Tau}^{2}=0 ; \mathrm{Chi}^{2}=1.56, \mathrm{df}=2(\mathrm{P}=0.46) ; \mathrm{I}^{2}=0 \%$} \\
\hline \multicolumn{6}{|c|}{ Test for overall effect: $Z=2.9(P=0)$} \\
\hline \multicolumn{6}{|c|}{ 2.1.2 Conventional cooling vs $36^{\circ}$ temperature management } \\
\hline Nielsen 2013 & $238 / 473$ & $241 / 466$ & & $100 \%$ & $0.97[0.86,1.1]$ \\
\hline Subtotal $(95 \% \mathrm{Cl})$ & 473 & 466 & & $100 \%$ & $0.97[0.86,1.1]$ \\
\hline \multicolumn{6}{|c|}{ Heterogeneity: Not applicable } \\
\hline \multicolumn{6}{|c|}{ Test for overall effect: $Z=0.43(P=0.67)$} \\
\hline \multicolumn{6}{|c|}{ 2.1.3 Cooling with haemofiltration vs no cooling } \\
\hline Laurent 2005 & $7 / 22$ & $9 / 20$ & & $100 \%$ & $0.71[0.32,1.54]$ \\
\hline Subtotal $(95 \% \mathrm{Cl})$ & 22 & 20 & & $100 \%$ & $0.71[0.32,1.54]$ \\
\hline \multicolumn{6}{|c|}{ Total events: 7 (cooling to $33^{\circ} \mathrm{C}$ ), 9 (Control) } \\
\hline \multicolumn{6}{|c|}{ Heterogeneity: Not applicable } \\
\hline \multicolumn{6}{|c|}{ Test for overall effect: $Z=0.87(P=0.38)$} \\
\hline \multicolumn{6}{|c|}{ Test for subgroup differences: $\mathrm{Chi}^{2}=8.27, \mathrm{df}=1(\mathrm{P}=0.02), \mathrm{I}^{2}=75.81 \%$} \\
\hline
\end{tabular}




\section{Analysis 2.2. Comparison 2 Survival: therapeutic hypothermia versus no hypothermia, Outcome 2 Conventional cooling.}

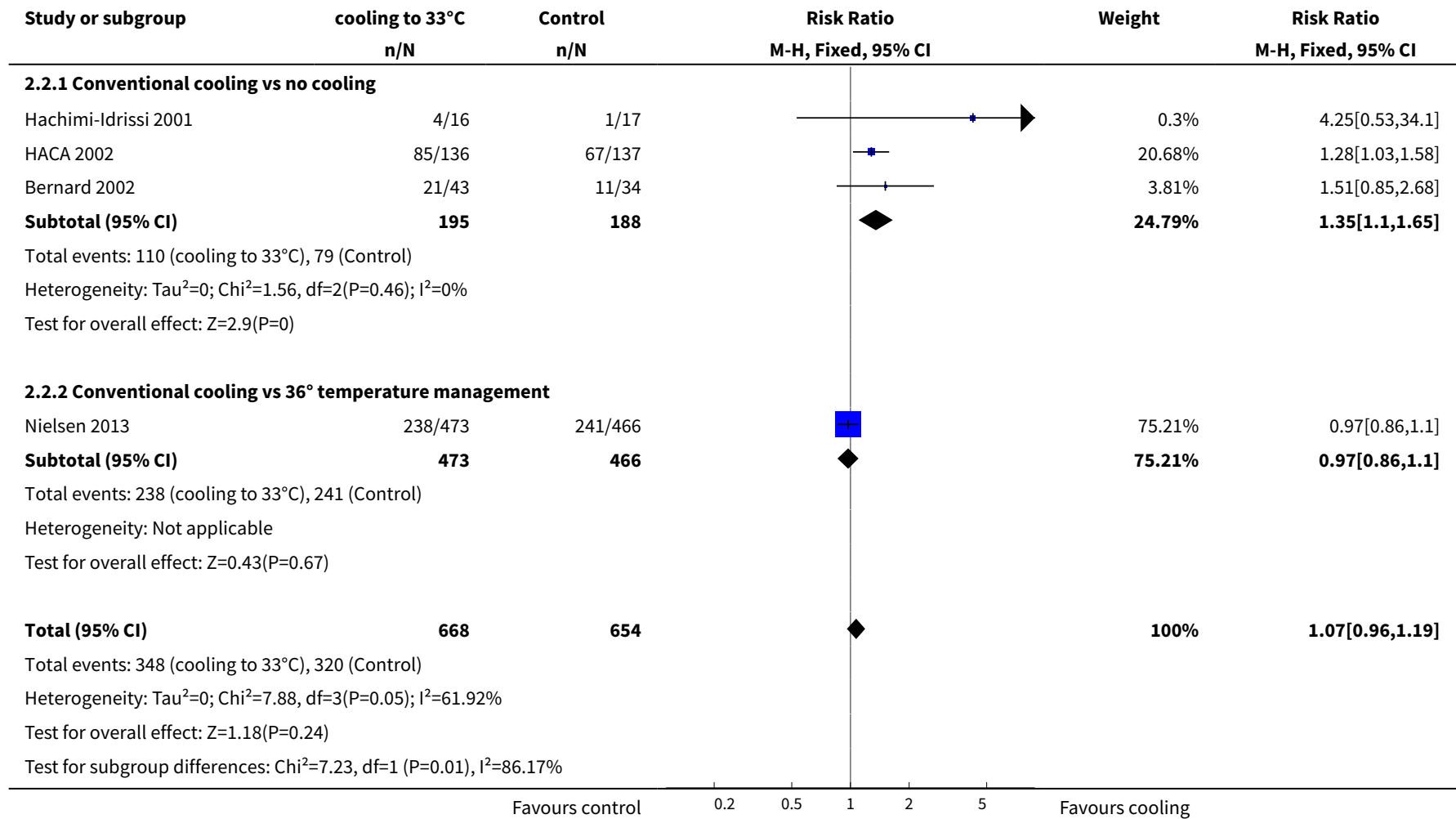

\section{ADDITIONAL TABLES}

Table 1. Subgroup analyses

\begin{tabular}{llll}
\hline Outcome or subgroup & Studies & Participants & Risk ratio (M-H, fixed, 95\% Cl) \\
\hline $\begin{array}{l}\text { Good neurological outcome by cardiac cause vs } \\
\text { non-cardiac cause }\end{array}$ & 3 & 383 & 1.54 (1.22 to 1.95) \\
\hline Cardiac cause & 3 & 372 & 1.51 (1.19 to 1.91) \\
\hline Non-cardiac cause & 2 & 11 & 3.80 (0.55 to 26.29) \\
\hline $\begin{array}{l}\text { Good neurological outcome by location of cardiac } \\
\text { arrest }\end{array}$ & 3 & 382 & 1.56 (1.23 to 1.98) \\
\hline $\begin{array}{l}\text { In-hospital } \\
\text { Out-of-hospital }\end{array}$ & 1 & 17 & 1.64 (0.47 to 5.73) \\
\hline $\begin{array}{l}\text { Good neurological outcome by witnessed cardiac } \\
\text { arrest }\end{array}$ & 3 & 365 & 1.56 (1.23 to 1.99) \\
\hline Witnessed cardiac arrest & 382 & 1.49 (1.18 to 1.88) \\
\hline \hline
\end{tabular}


Table 1. Subgroup analyses (Continued)

\begin{tabular}{lccc} 
Non-witnessed cardiac arrest & 3 & 22 & 5.31 (1.40 to 20.21) \\
\hline $\begin{array}{l}\text { Good neurological outcome by primary ECG } \\
\text { rhythm }\end{array}$ & 3 & 382 & 1.51 (1.19 to 1.91) \\
\hline VF/VT rhythm & 2 & 330 & 1.47 (1.15 to 1.88) \\
\hline Non- VF/VT rhythm & 2 & 52 & 2.17 (0.68 to 6.93) \\
\hline
\end{tabular}

$E C G=$ electrocardiogram

VF/VT = ventricular fibrillation/ventricular tachycardia

Table 2. Sensitivity analysis

\begin{tabular}{llll}
\hline Outcome or subgroup & Studies & Participants & $\begin{array}{c}\text { Risk ratio } \\
\text { (M-H, Fixed, 95\% Cl) }\end{array}$ \\
\hline $\begin{array}{l}\text { Good neurological outcome for all studies with conventional cool- } \\
\text { ing }\end{array}$ & 4 & 437 & $1.94(1.18$ to 3.21$)$ \\
\hline $\begin{array}{l}\text { Studies with conventional cooling and adequate or unknown allo- } \\
\text { cation concealment }\end{array}$ & 3 & 360 & $2.46(0.96$ to 6.28) \\
\hline $\begin{array}{l}\text { Studies with conventional cooling and adequate allocation con- } \\
\text { cealment }\end{array}$ & 2 & 445 & $1.97(0.71$ to 5.45) \\
\hline $\begin{array}{l}\text { Studies with other cooling methods and adequate allocation con- } \\
\text { cealment }\end{array}$ & 1 & 42 & $0.71(0.32$ to 1.54$)$ \\
\hline
\end{tabular}

Table 3. Adverse effects

\begin{tabular}{llll}
\hline Outcome or subgroup & Studies & Participants & Risk ratio \\
(M-H, Fixed, 95\% Cl)
\end{tabular}


Table 3. Adverse effects (Continued)

\begin{tabular}{lccc} 
Seizures & 2 & 1202 & 1.18 (0.98 to 1.42) \\
\hline Lethal or long-lasting arrhythmia & 2 & 315 & 1.21 (0.88 to 1.67) \\
\hline Any arrhythmia & 1 & 933 & 0.98 (0.93 to 1.04) \\
\hline Pulmonary oedema & 1 & 269 & 1.76 (0.61 to 5.12) \\
\hline Cardiac complications & 1 & No totals \\
\hline Hypokalaemia & 2 & 975 & 1.38 (1.03 to 1.84) \\
\hline Hypophosphataemia & 2 & 975 & 1.10 (0.92 to 1.33) \\
\hline Hypoglycaemia & 1 & 933 & 1.12 (0.64 to 1.97) \\
\hline Hypomagnesaemia & 1 & 933 & 1.20 (0.88 to 1.65) \\
\hline Pressure sores & 1 & 269 & Not estimable \\
\hline
\end{tabular}

\section{APPENDICES}

\section{Appendix 1. Search strategy: CENTRAL, The Cochrane Library}

\#1 MeSH descriptor Resuscitation explode all trees

\#2 MeSH descriptor Cardiopulmonary Resuscitation explode all trees

\#3 MeSH descriptor Resuscitation Orders explode all trees

\#4 MeSH descriptor Heart Arrest explode all trees

\#5 MeSH descriptor Heart Massage explode all trees

\#6 ((cardio?pulmonary or order $\left.{ }^{\star}\right)$ near2 resuscitation):ti,ab

\#7 reanimation:ti,ab

\#8 ((circulatory or circulation or cardiac) near arrest):ti,ab or heart standstill:ti,ab

\#9 (\#1 OR \#2 OR \#3 OR \#4 OR \#5 OR \#6 OR \#7 OR \#8)

$\# 10 \mathrm{MeSH}$ descriptor Cryotherapy explode all trees

\#11 MeSH descriptor Hypothermia explode all trees

\#12 MeSH descriptor Hypothermia, Induced explode all trees

\#13 ((resuscitative or therapeutic or artificial or induced or extracorporeal) near hypothermia)

\#14 artificial hibernation or body cooling or refrigeration anesthesia or body temperature:ti,ab or refrigeration:ti,ab

\#15 (\#10 OR \#11 OR \#12 OR \#13 OR \#14)

\#16 (\#9 AND \#15)

\section{Appendix 2. Search strategy: MEDLINE (Ovid SP)}

1. Resuscitation/ or Cardiopulmonary Resuscitation/ or Resuscitation Orders/ or Heart Arrest/ or Heart Massage/ or advanced cardiac life support.mp. or ((cardio?pulmonary or order $\left.{ }^{\star}\right)$ adj2 resuscitation).ti,ab. or reanimation.ti,ab. or ((circulatory or circulation or cardiac) adj3 arrest).ti,ab. or heart standstill.ti,ab.

2. Cryotherapy/ or Hypothermia/ or Circulatory Arrest, Deep Hypothermia Induced/ or Hypothermia, Induced/ or ((resuscitative or therapeutic or artificial or induced or extracorporeal) adj3 hypothermia).mp. or artificial hibernation.mp. or body cooling.mp. or chilling.mp. or refrigeration anesthesia.mp. or body temperature.ti,ab. or refrigeration.ti,ab.

3. 1 and 2

4. ((randomised controlled trial or controlled clinical trial).pt. or randomised.ab. or placebo.ab. or clinical trials as topic.sh. or randomly.ab. or trial.ti.) not (animals not (humans and animals)).sh.

5.3 and 4 


\title{
Appendix 3. Search strategy: EMBASE (Ovid SP)
}

1. resuscitation/ or heart arrest/ or heart massage/ or advanced cardiac life support.mp. or ((cardio?pulmonary or order $\left.{ }^{\star}\right)$ adj2 resuscitation).ti,ab. or reanimation.ti,ab. or ((circulatory or circulation or cardiac) adj3 arrest).ti,ab. or heart standstill.ti,ab.

2. cryotherapy/ or hypothermia/ or ((resuscitative or therapeutic or artificial or induced or extracorporeal) adj3 hypothermia).mp. or artificial hibernation.mp. or body cooling.mp. or chilling.mp. or refrigeration anesthesia.mp. or body temperature.ti,ab. or refrigeration.ti,ab.

3. 1 and 2

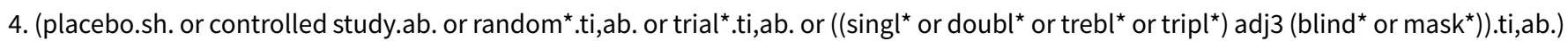
not (animals not (humans and animals)).sh.

5.3 and 4

\section{Appendix 4. Search strategy: CINAHL (EBSCO Host)}

S1 ( (MH "Resuscitation") OR (MH "Resuscitation Orders") OR (MH "Resuscitation, Cardiopulmonary") OR (MH "Heart Arrest") OR (MH "Heart Massage") ) OR AB ( ((cardio?pulmonary or order ${ }^{\star}$ ) and resuscitation) ) OR AB reanimation OR ( (circulatory or circulation or cardiac) and arrest ) OR heart standstill

S2 ( (MH "Cryotherapy") OR (MH "Hypothermia") OR (MH "Hypothermia, Induced")) OR ( ((resuscitative or therapeutic or artificial or induced or extracorporeal) and hypothermia) ) OR artificial hibernation OR body cooling OR refrigeration anesthesia

S3 ( (MH "randomised Controlled Trials") OR (MH "Random Assignment") OR (MH "Prospective Studies") OR (MH "Multicenter Studies") OR (MH "Clinical Trials") OR (MH "Clinical Trial Registry") OR (MH "Double-Blind Studies") OR (MH "Single-Blind Studies") OR (MH "TripleBlind Studies") OR (MH "Placebos") ) OR ( random* or controlled clinical trial or placebo )

S4 S1 and S2 and S3

\section{Appendix 5. Search strategy: BIOSIS (Ovid SP)}

1. advanced cardiac life support.mp. or ((cardio?pulmonary or order $\left.{ }^{\star}\right)$ adj2 resuscitation).ti,ab. or reanimation.ti,ab. or ((circulatory or circulation or cardiac) adj3 arrest).ti,ab. or heart standstill.ti,ab.

2. (((resuscitative or therapeutic or artificial or induced or extracorporeal) adj3 hypothermia) or artificial hibernation or body cooling or chilling or refrigeration anesthesia).mp. or body temperature.ti,ab. or refrigeration.ti,ab.

3. 1 and 2

\section{Appendix 6. Data extraction form}

\author{
Data extraction sheet \\ Hypothermia for neuroprotection after cardiopulmonary resuscitation \\ Update review
}

\section{Reviewer:}

Date:

\begin{tabular}{ll}
\hline Decision: & $\begin{array}{l}\cdot \text { inclusion } \\
\text { exclusion }\end{array}$ \\
\hline Reasons for exclusion: & \\
\hline Study characteristics & Publication type: \\
\hline Setting & Language \\
& Multi-centre: \\
& $\cdot$ yes \\
\hline
\end{tabular}

Participating sites:

- university 
(Continued)

- community hospitals

- other, please specify

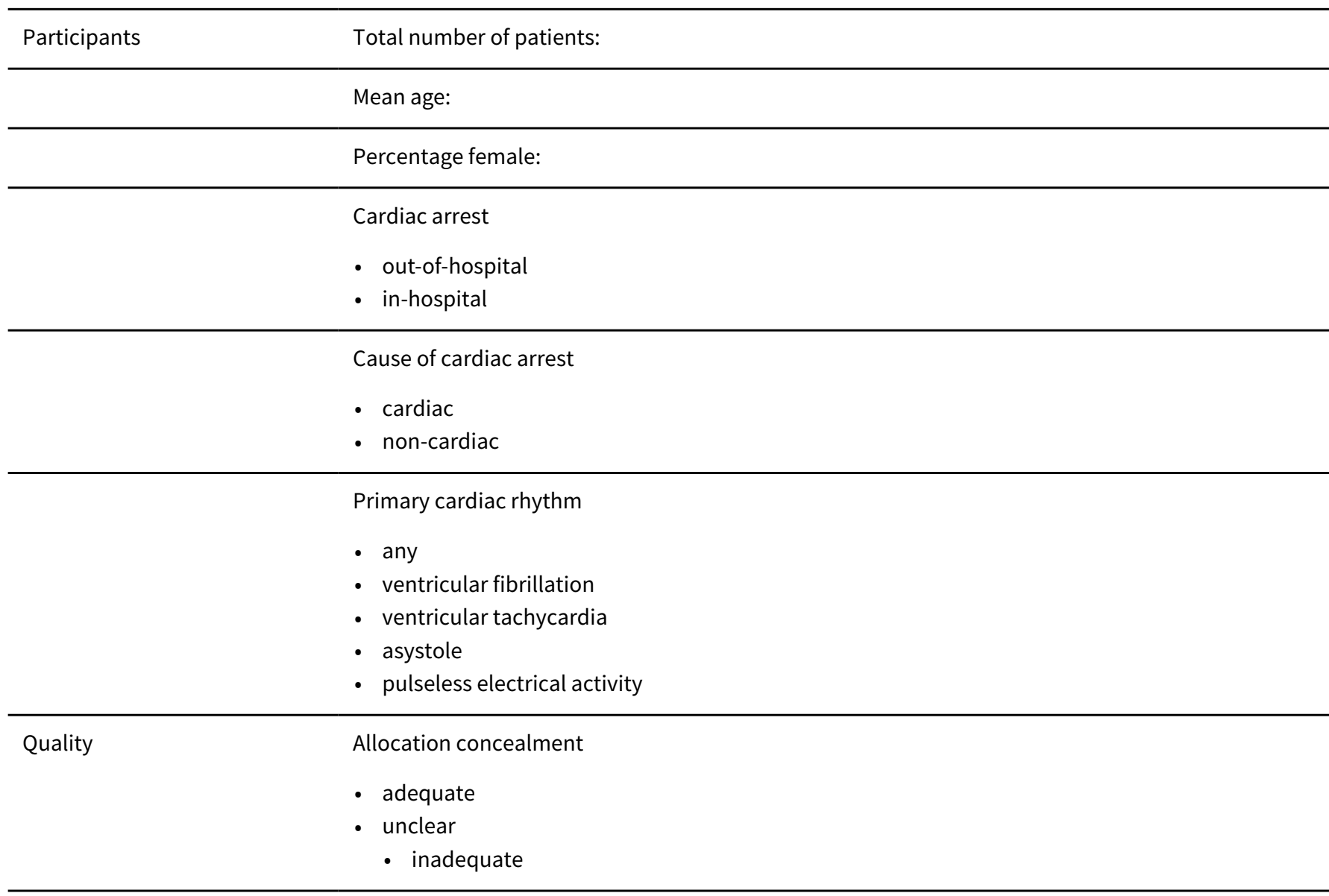

Outcome assessor blind

- yes

- no

- if unclear, please explain

Intention-to-treat:

- yes

- no

- if unclear, please explain

Groups comparable:

- yes

- if not, please specify

Follow-up $>80 \%$ of randomly assigned participants:

- yes

- if not, please specify 
(Continued)

Controls:

Time from restoration of spontaneous circulation to target temperature:

Cooling rate:

Duration of cooling:

Rewarming:

Outcomes Types of outcome measures:

- ..

- ..

- ..

Time point of assessment of outcome measures:

- .

- .

- .

\section{Funding}

\section{Notes}

\section{Risk of bias assessment}

\begin{tabular}{ll}
\hline Allocation concealment & Short description: \\
& rating \\
& - low risk \\
& - unclear risk \\
& high risk \\
\hline
\end{tabular}

Inclusion/exclusion explicitly reported: Short description:

rating

- low risk

- unclear risk

- high risk

$\begin{array}{ll}\text { Intention-to-treat: } & \text { Short description } \\ & \text { rating } \\ & \text { - low risk } \\ & \text { - unclear risk } \\ & \text { - high risk }\end{array}$

Appropriate participant description

Short description:

rating 
(Continued)
- low risk
- unclear risk
- high risk

\begin{tabular}{ll}
\hline Identical care & Short description \\
& rating \\
& - low risk \\
& unclear risk \\
& - high risk
\end{tabular}

\begin{tabular}{ll}
\hline Outcomes appropriately defined: & Short descriptio \\
& rating \\
& - low risk \\
& - unclear risk \\
& - high risk
\end{tabular}

\begin{tabular}{ll}
\hline Follow-up $>80 \%:$ & Short description: \\
& rating \\
& - low risk \\
& - unclear risk \\
& - high risk
\end{tabular}

Physician blinded: Short description:

rating

- low risk

- unclear risk

- high risk

\begin{tabular}{ll}
\hline Outcome assessor blinded & Short description: \\
(outcomes other than mortality): & rating \\
& - low risk \\
& - unclear risk \\
& high risk
\end{tabular}

Other risks of bias Short description:

Results primary:

\section{Type of outcome:}

\begin{tabular}{llll}
\hline Cooling & & No cooling & \\
\hline Events $(\mathrm{n})$ & Total $(\mathrm{N})$ & Events $(\mathrm{n})$ & Total (N) \\
\hline
\end{tabular}


Results secondary:

\section{Type of outcome:}

\begin{tabular}{llll}
\hline Cooling & & No cooling & \\
\hline Events $(\mathrm{n})$ & Total $(\mathrm{N})$ & Events $(\mathrm{n})$ & Total $(\mathrm{N})$ \\
\hline
\end{tabular}

\section{WHAT'S NEW}

\begin{tabular}{lll}
\hline Date & Event & Description \\
\hline 13 December 2018 & Amended & Editorial team changed to Cochrane Emergency and Critical Care \\
\hline
\end{tabular}

\section{H I S T ORY}

Protocol first published: Issue 2, 2003

Review first published: Issue 4, 2009

\begin{tabular}{lll}
\hline Date & Event & Description \\
\hline 15 February 2016 & New search has been performed & $\begin{array}{l}\text { We updated references (deleted Westfal 1996; added McNally } \\
\text { 2011) }\end{array}$ \\
\hline
\end{tabular}

15 February $2016 \quad$ New citation required but conclusions have not changed
This review is the second update of a previous Cochrane systematic review (Arrich 2009) that included 4 trials and 1 abstract reporting on 481 participants. The first update of 2012 (Arrich 2012) included the same studies and participants

In the previous version (Arrich 2012), we searched the databases until July 2011. In this updated version, we reran searches to May 2015. Since that time, 1 randomized controlled trial (RCT) was published (Nielsen 2013) and we have gained more information on another RCT (Mori 2000), so that we were able to include it in the main analysis

We had to limit the individual patient data (IPD) analysis to subgroup analyses

The conclusion for the primary outcome of "neurological outcome" has not changed substantially

No review authors have joined or left the team

31 July $2012 \quad$ New search has been performed

This review is an update of a previous Cochrane systematic review (Arrich 2009) that included 4 trials and 1 abstract reporting on 481 participants 


\begin{tabular}{|c|c|c|}
\hline Date & Event & Description \\
\hline & & $\begin{array}{l}\text { In the previous version (Arrich 2009), we searched the databases } \\
\text { until January 2009. In this updated version, we reran searches to } \\
\text { July } 2011\end{array}$ \\
\hline & & $\begin{array}{l}\text { We updated Methods, allocated all chapters, updated references } \\
\text { and added a risk of bias table and a summary of findings table }\end{array}$ \\
\hline & & $\begin{array}{l}\text { A typing error (survival instead of neurological outcome) in the } \\
\text { Results section was spotted by a reader and was corrected ac- } \\
\text { cordingly }\end{array}$ \\
\hline 31 July 2012 & $\begin{array}{l}\text { New citation required but conclusions } \\
\text { have not changed }\end{array}$ & We added Christof Havel as a review author \\
\hline 28 June 2010 & Amended & We updated contact details \\
\hline 29 October 2009 & Amended & We corrected a typo in a co-review author's address (Müllner) \\
\hline
\end{tabular}

\section{CONTRIBUTIONS OF AUTHORS}

Conceiving of review and update: Harald Herkner (HH), Michael Holzer (MH), Marcus Müllner (MM), Christof Havel (CH).

Co-ordinating the review: $\mathrm{HH}$, Jasmin Arrich (JA).

Undertaking manual searches: $\mathrm{MH}, \mathrm{JA}$.

Screening search results: $\mathrm{MH}, \mathrm{JA}, \mathrm{CH}$.

Organizing retrieval of papers: JA.

Screening retrieved papers against inclusion criteria: $\mathrm{MH}, \mathrm{JA}, \mathrm{MM}, \mathrm{CH}$.

Appraising quality of papers: $\mathrm{MH}, \mathrm{HH}, \mathrm{JA}, \mathrm{MM}, \mathrm{CH}$.

Abstracting data from papers: $\mathrm{MH}, \mathrm{JA}, \mathrm{CH}$.

Writing to authors of papers for additional information: MH, JA.

Providing additional data about papers: $\mathrm{MH}, \mathrm{JA}$.

Obtaining and screening data on unpublished studies: $\mathrm{MH}, \mathrm{JA}$.

Managing data for the review: $\mathrm{HH}, \mathrm{JA}, \mathrm{MM}$.

Entering data into Review Manager (RevMan 5.3): MH, JA.

Analysing RevMan statistical data: $\mathrm{HH}, \mathrm{MM}, \mathrm{JA}$.

Performing other statistical analyses not using RevMan: HH, MM.

Performing double entry of data: $\mathrm{MH}, \mathrm{JA}$.

Interpreting data: $\mathrm{MH}, \mathrm{HH}, \mathrm{JA}, \mathrm{MM}, \mathrm{CH}$.

Making statistical inferences: $\mathrm{HH}, \mathrm{MM}, \mathrm{JA}$.

Writing the review: JA, MM, $\mathrm{HH}$.

Securing funding for the review: not applicable.

Performing previous work that served as the foundation of the present study: $\mathrm{MM}, \mathrm{MH}, \mathrm{CH}$.

Serving as guarantor for the review (one review author): JA.

Taking responsibility for reading and checking the review before submission: $\mathrm{HH}$.

\section{DECLARATIONS OF INTEREST}

Jasmin Arrich has no conflicts of interest.

Michael Holzer received travel grants for scientific conferences and honoraria for lectures from Bard Medical, EmCools, Polimed Sp. z 0.o. and Zoll Medical Österreich. He received honoraria for consulting from Zoll Medical Österreich and was responsible for studies for which the Department of Emergency Medicine received study grants from Velomedix and Philips.

Marcus Müllner, Michael Holzer and Christof Havel were involved in the design, conduct and publication of the HACA 2002 trial. None of the authors of the HACA 2002 trial extracted data from that trial.

Harald Herkner has no conflicts of interest. 


\section{SOURCES OF SUPPORT}

\section{Internal sources}

- Medical University of Vienna, Austria.

\section{External sources}

- No sources of support supplied

\section{DIFFERENCES BETWEEN PROTOCOLAND REVIEW}

\section{Update 2015}

We did not search the PASCAL database, as it was no longer available at our institution. We additionally searched three trial registers (EudraCT, ClinicalTrials.gov and the International Clinical Trials Registry Platform).

\section{Update 2012 (Arrich 2012)}

In our protocol (Arrich 2003), we aimed to include additional endpoints such as six-month and final CPC scores, long-term mortality, quality of life at six months, long-term dependency and cost-effectiveness. Retrieved studies provided no information on long-term mortality, quality of life or cost-effectiveness.

All studies included in the individual patient analysis provided data on both best and final neurological outcome (Bernard 2002; HACA 2002; Hachimi-Idrissi 2001). In our opinion, the 'best neurological score during hospital stay' is superior to the final score, as the final score may be influenced by other factors such as worsening of body functions or re-arrests.

Bernard 2002 and Hachimi-Idrissi 2001 provided information on survival to hospital discharge, HACA 2002 additionally on six-month survival and Laurent 2005 only on six-month survival. As the study by Laurent was not included in individual patient analyses, we chose survival to hospital discharge as a secondary endpoint for the individual patient analysis.

Documentation of adverse effects was overlooked in the original protocol. As they form a vital part of every review, we included adverse effects on the data extraction sheet before we performed the literature search.

In accordance with our reviewers, to better explain the reasons for dual analysis and the way it was carried out, we have changed the wording of the objectives from

"The aim of this study is to present a systematic review of the literature and, if applicable, a meta-analysis, concerning the neuroprotective effect of induced hypothermia in primary cardiac arrest survivors. We plan to use data at the aggregate (study) level and the individual (patient) level."

to

"We aimed to perform a systematic review and meta-analysis to assess the effectiveness of therapeutic hypothermia in participants after cardiac arrest. neurological outcome, survival and adverse events were our main outcomes. We aimed to perform individual patient data analysis if data were available. We intended to form subgroups according to the cardiac arrest situation."

The title has been changed from "Hypothermia for neuroprotection after cardiopulmonary resuscitation" to "Hypothermia for neuroprotection in adults after cardiopulmonary resuscitation".

\section{NOTES}

May 2015: We adopted the GRADE approach for our review.

We would like to thank Dr Mathew Zacharias (Content Editor), Dr Marialena Trivella (Statistical Editor) and Dr Malcolm G Booth, Dr George Djaiani and Shafi Mussa (Peer Reviewers) for help and editorial advice provided during preparation of the earlier version of this review (Arrich 2009).

We would also like to thank Dr Mathew Zacharias, Dr Marialena Trivella, Dr Malcolm Booth, Dr Karen Rees, Prof Ian Jacobs and Jane Cracknell for help and editorial advice provided during preparation of the protocol (Arrich 2003) for the systematic review. 


\section{N D X T ERMS}

\section{Medical Subject Headings (MeSH)}

Brain Diseases [ ${ }^{*}$ prevention \& control]; Cardiopulmonary Resuscitation [ ${ }^{*}$ adverse effects]; Heart Arrest [ ${ }^{*}$ complications] [therapy]; Hypokalemia [etiology]; Hypothermia, Induced [adverse effects] [ ${ }^{*}$ methods]; Hypoxia, Brain [prevention \& control]; Pneumonia [etiology]; Randomized Controlled Trials as Topic; Recovery of Function

\section{MeSH check words}

Adult; Humans 